NBER WORKING PAPER SERIES

\title{
LABOR RATIONING
}

\author{
Emily Breza \\ Supreet Kaur \\ Yogita Shamdasani \\ Working Paper 28643 \\ http://www.nber.org/papers/w28643
}

\author{
NATIONAL BUREAU OF ECONOMIC RESEARCH \\ 1050 Massachusetts Avenue \\ Cambridge, MA 02138 \\ April 2021
}

We thank Abhijit Banerjee, David Card, Andrew Foster, Jessica Goldberg, Pat Kline, Jeremy Magruder, Ben Olken, Duncan Thomas, and many seminar participants for helpful comments and conversations. We thank Arnesh Chowdhury, Piyush Tank, Silvia Wang, Mohar Dey, Anshuman Bhargava, Vibhuti Bhatt, Asis Thakur, and Anustubh Agnihotri for excellent research assistance. We gratefully acknowledge financial support from the National Science Foundation. The views expressed herein are those of the authors and do not necessarily reflect the views of the National Bureau of Economic Research.

NBER working papers are circulated for discussion and comment purposes. They have not been peer-reviewed or been subject to the review by the NBER Board of Directors that accompanies official NBER publications.

(C) 2021 by Emily Breza, Supreet Kaur, and Yogita Shamdasani. All rights reserved. Short sections of text, not to exceed two paragraphs, may be quoted without explicit permission provided that full credit, including (C) notice, is given to the source. 
Labor Rationing

Emily Breza, Supreet Kaur, and Yogita Shamdasani

NBER Working Paper No. 28643

April 2021

JEL No. E24,J2,J6,O10,O17

\title{
$\underline{\text { ABSTRACT }}$
}

This paper measures excess labor supply in equilibrium. We examine hiring shocks—which employ $24 \%$ of the labor force in external month-long jobs-in Indian local labor markets. In peak months, wages increase instantaneously and local aggregate employment declines. In lean months, consistent with severe labor rationing, wages and aggregate employment are unchanged, with positive employment spillovers on remaining workers-indicating that over a quarter of labor supply is rationed. At least $24 \%$ of lean self-employment among casual workers occurs because they cannot find jobs. Consequently, traditional survey approaches mismeasure labor market slack. Rationing has broad implications for labor market analysis.

\author{
Emily Breza \\ Harvard University \\ Littauer Center, M28 \\ 1805 Cambridge Street \\ Cambridge, MA 02138 \\ and NBER \\ ebreza@fas.harvard.edu \\ Supreet Kaur \\ Department of Economics \\ University of California, Berkeley \\ Evans Hall \\ Berkeley, CA 94720 \\ and NBER \\ supreet@berkeley.edu
}

\author{
Yogita Shamdasani \\ National University of Singapore \\ yogita@nus.edu.sg
}




\section{INTRODUCTION}

$[D]$ istinguishing elements of voluntariness from elements of involuntariness in the unemployment problem is a hopeless endeavour. (Fellner, 1976)

In developing countries, wage employment rates among rural workers often hover around $50 \%$. For example, Indian landless prime age males - whose primary source of earnings is wage labor - work $45.7 \%$ of the time (NSS 2009). In Bangladesh, wage employment rates for landless males are about 55\% in lean months (Akram et al., 2018). In Sub Saharan Africa, these rates are typically even lower (Beegle and Christiaensen, 2019).

The interpretation of this empirical regularity is unclear, and has long been a source of debate. Research going back to Lewis (1954) argues that low employment reflects extremely high involuntary unemployment, indicating large distortions. However, other work has shown that these labor markets adjust rapidly to changing market conditions (e.g., Rosenzweig, 1988). Thus, low wage work might instead be the outcome of reasonably well-functioning labor markets, where workers are simply choosing other activities such as self-employment. These two possibilities have drastically different implications for the labor market equilibrium. Moreover, while the development labor literature has documented frictions - giving rise to separation failures, labor misallocation, and downward wage rigidity (e.g., LaFave and Thomas, 2016; Bryan et al., 2014; Kaur, 2019) - knowing that these exist does not tell us about the extent of aggregate distortions in equilibrium. In other words, existing work cannot explain how one should interpret observed employment patterns. Specifically, whether there is a large amount of labor rationing in this setting still remains unknown.

This paper empirically assesses the extent to which labor supply exceeds labor demand in equilibrium. For concreteness, we define a worker as rationed if: a) she would prefer wage employment at the current market wage over what she is doing (i.e. the worker is not on her labor supply curve), and b) the worker is employable at that wage (i.e. from the employer's perspective, her marginal product is weakly above the current wage). A rationed worker may be involuntarily unemployed, or engaged in another activity such as self-employment.

Determining the amount of rationing presents challenges under current approaches. To measure involuntary unemployment, economists use survey self-reports - whether an individual was looking for a job but could not find one. However, the validity of this approach has been questioned, and remains unknown (e.g. Bound et al., 2001; Taylor, 2008). These challenges are exacerbated in developing countries, where self-employment is prevalent and can absorb workers who cannot find jobs. While previous work discusses the presence of such "disguised" or "hidden" unemployment, we currently have no estimates of whether a sizable fraction of self-employment is due to rationing in the wage labor market. 
We tackle these fundamental measurement problems by developing a simple revealed preference approach to test for excess labor supply (i.e. labor rationing). We induce transitory hiring shocks in Indian local labor markets - giving jobs to on average $24 \%$ of the labor force of casual male workers in external jobsites for 2-4 weeks. This shock substantively reduces how many workers remain in the local economy, without changing local labor demand. ${ }^{1}$ We then use the local labor market response to learn about the equilibrium that existed in the absence of our shock. We take seriously the idea that seasonality in labor demand may be consequential for labor market functioning (Leibenstein, 1957), with relevance for understanding seasonal fluctuations in employment levels (Bryan et al., 2014; Fink et al., 2018). Consequently, we undertake this exercise across the year - enabling us to test for excess supply separately across lean and peak months.

This approach uncovers labor market functioning without direct intervention on the participants of interest. While we exogenously generate shocks, the outcomes are driven completely by the response of existing employers and workers who never interface with the external jobsites. We use the phrase "local labor market" to denote all jobs, wages, and employment excluding the external worksite jobs we create. If the level of rationing is higher than the size of our shock - e.g., if we remove $25 \%$ of the labor force and more than $25 \%$ of worker-days are rationed - then we would expect the following local labor market impacts: i) no change in wage levels; ii) no effect on aggregate employment; and iii) positive employment spillovers on individual workers whose employment goes up due to less competition for jobs. This constitutes a revealed preference test of rationing driven by a failure of wage adjustment. Specifically, workers reveal they prefer jobs at the market wage over their previous activity (e.g. unemployment or self-employment), and employers reveal the worker is qualified for a job at the market wage. If these predictions hold, the size of our hiring shock is a lower bound on the level of excess labor supply in the economy.

This design diagnoses rationing without assumptions about the equilibrium in the absence of rationing - for example, whether it is fully competitive or subject to monopsony or some other friction. We view this as a strength of our approach, and do not make direct claims regarding potential other frictions.

The setting for our test is rural labor markets in Odisha, India, which exhibit many features of developing country village economies - including low wage employment and high seasonality. We conduct the experiment using a matched-pair, stratified design in 60 labor markets (i.e. villages) across varying times of the year. We invite workers to sign up for employment at

\footnotetext{
${ }^{1}$ We discuss the possibility of multiplier effects from demand below.
} 
external worksites, drawing signups by a large proportion of the labor force. ${ }^{2}$ We randomize the intensity of hiring across villages: in treated villages, we provide jobs to on average $24 \%$ of the labor force of male workers; in control villages, we hire 1-5 workers only. In each case, we randomly choose which workers are "removed" from among the signups.

What is the impact of removing about a quarter of workers on the local labor market? The answer depends crucially on seasonality.

During "peak" months - when employment is above median - the equilibrium wage rises by 5.0 percent. In addition, local aggregate employment declines by 4.3 percentage points or $21 \%$. In the peak season, each day of work created in external jobsites generates 0.737 days of new work for laborers in the economy overall (i.e. crowds out 0.263 days in the local labor market). It is worth noting that this wage and employment response is almost instantaneous - occurring within just a week of the start of the transitory hiring shock. This indicates a remarkably high level of labor market responsiveness, and accords with the view that spot labor markets in these settings can quickly reflect changes in market conditions (Rosenzweig, 1988).

In sharp contrast, effects during "lean" months - when employment is below median-match predictions under severe labor rationing. Removing a quarter of the labor force has no effect on wages or aggregate employment (predictions (i) and (ii) above). In other words, creating external jobs for a quarter of workers generates no crowd-out in the private labor market in the lean season. Consistent with prediction (iii), there are large positive employment spillovers on the workers remaining in the local labor market; the employment rate for these workers goes up by 5.4 percentage points (38\%). This follows from the fact that there is no change in aggregate employment: workers who would otherwise have been rationed fill in job slots that are available because many others have become employed outside the village. External employment therefore helps not only those who received our worksite jobs, but also those who did not. Overall, our results indicate that on average, at least a quarter of male labor supply is rationed out of the wage labor market in lean months.

These lean season spillover effects are transitory-lasting only as long as the hiring shocks do. This is what one would expect if the response to our hiring shock was due to excess labor supply. It also helps rule out, for example, a wealth effect explanation for our results. ${ }^{3}$

A large portion of excess labor supply is disguised as self-employment. In lean months, we see a 3.4 percentage point, or $24 \%$, decline in self-employment among those who sign

\footnotetext{
${ }^{2}$ We offer relatively high wages for desirable manufacturing jobs. This is beneficial for our design, enabling us to draw (random) workers from across the skill distribution in the village.

${ }^{3}$ Also consistent with rationing, the wage increase in peak months persists after the shock ends, leading to lower employment - in line with a ratcheting effect from downward wage rigidity (Kaur, 2019).
} 
up for worksite jobs. By revealed preference, these business owners prefer wage labor at the prevailing wage to working in their businesses. This implies that in our sample, in the lean season, at least $24 \%$ of self-employment stems from workers being rationed out of wage labor. Among farm households, these effects are entirely concentrated among those with below median per-capita landholdings - the group we would expect to be most affected by a ration in the labor market. Workers in these households reduce self-employment by 7.2 percentage points (50\%)-indicating that on small farms, half of self-employment in lean months is driven by rationing. Like the employment spillovers, these effects are also transitory. Once the shock ends, self-employment levels between treatment and control villages are indistinguishable - ruling out the concern that business owners simply intertemporally substitute by increasing self-employment in the future.

Finally, we examine traditional survey-based unemployment measures. Despite the sizable impacts on wage employment, overall work status does not move in lean months - precisely due to disguised unemployment. In addition, if we mimic the approach for measuring involuntary unemployment used in government surveys (including India's National Sample Survey), we would conclude that our shocks had no impact on unemployment in lean months. We evaluate an alternate survey measure, and find its movement matches the revealed preference magnitudes. However, our findings suggest that, in our setting, traditional survey questions will mismeasure the extent to which individuals are unable to find wage work.

We argue that other potential mechanisms through which the shocks could affect wages or employment - such as a local demand expansion from increased wealth, or a change in worker composition - cannot explain our pattern of results. We also offer direct tests for such potential confounds, and rule out perfectly elastic labor supply. In addition, we evaluate potential micro-foundations for excess labor supply — such as efficiency wages, dynamic contracting, implicit insurance, and worker collective action - in light of our findings.

Overall, the patterns we document are consistent with the hypothesis of "under-utilized labor" proposed by Leibenstein (1957). If the labor market, and particularly the wage, does not adjust fully to seasonal reductions in labor demand, this can generate rationing in lean periods. While our estimates are of course specific to our particular context, the pattern of differences in labor market functioning across peak and lean times is likely more general. Similar dynamics plausibly prevail in many rural, developing country settings.

Our results have implications for labor market policies, such as workfare-implying that crowd-out will depend crucially on the level of slack. In a suggestive exercise, we examine the phased-in roll-out of India's workfare program, NREGA (Imbert and Papp, 2015). When slack is higher (i.e. baseline district-month employment is lower), NREGA has no detectable 
impact on wages or private employment. However, when the labor market is tighter, wages rise and agricultural employment falls by almost 20\%, indicating substantial crowd out. These patterns match our experimental findings. Note that we don't rule out the possibility of lean season wage increases more generally: if a shock is larger than the number of rationed workers or changes reservation wages, wages could rise even in lean times.

This paper provides novel evidence on the functioning of labor markets in poor countries. It offers the first direct evidence that labor supply substantively exceeds labor demand in equilibrium. The earliest work in development, such as the surplus labor hypothesis, was premised on the view that rural economies have large slack (Lewis, 1954). The empirical relevance of this view has been unclear, especially in modern times. We document considerable slack, indicating that at least a quarter of labor supply is rationed during lean months. These findings suggest that moving rural workers to other sectors - where their labor may be more readily absorbed - could increase aggregate output not simply due to TFP differences between sectors (Gollin et al., 2014; McMillan and Rodrik, 2011), but also by enabling rationed workers to be employed. ${ }^{4}$

We also provide the first estimates of how much of self-employment is actually "disguised unemployment" (i.e., "forced entrepreneurship"). A striking share of self-employment in our sample $-23 \%$ on average and $75 \%$ among smallholder farms - would not occur if business owners could find work at the prevailing wage in lean months. This helps further our understanding of a prominent empirical fact: why self-employment is so high in poor countries (e.g. Banerjee and Duflo, 2007; De Mel et al., 2010). ${ }^{5}$

Relatedly, we advance the literature on labor market frictions in poor countries. A large body of work has examined separation failures (Singh et al., 1986; Benjamin, 1992; Fafchamps, 1993; Udry, 1996; LaFave and Thomas, 2016; Dillon et al., 2019; Jones et al., 2020; LaFave et al., 2020). These studies do not take a stance on the exact distortion that generates the failure - rationing or some other friction. ${ }^{6}$ They also do not quantify how many firms are affected. ${ }^{7}$ Our findings complement this work by tracing the first direct link from labor rationing to separation failures, and showing that rationing increases self-employment on

\footnotetext{
${ }^{4}$ Our design relates to tests of surplus labor (Schultz, 1964; Sen, 1967; Donaldson and Keniston, 2016). While other work has documented low employment levels during lean months, our study is the first to link this to rationing, rather than simply market clearing with low employment demand. Note that the presence of rationing complicates the interpretation of analyses that rely on wage differences across sectors to infer TFP differences.

${ }^{5}$ Adhvaryu et al. (2019) document that coffee farmers increase non-agricultural self-employment when farming becomes less profitable, though this does not require any market frictions such as rationing.

${ }^{6}$ See Behrman (1999) for a review. Pitt and Rosenzweig (1986) test a different microfoundation: productivity of own vs. hired labor. Foster and Rosenzweig (2017) examine the implications of transaction costs in hiring. ${ }^{7}$ E.g., the comparative static of whether household size affects farm labor use tests for a failure of separability, but does not shed light on whether the associated labor supply distortion affects $1 \%$ or $50 \%$ of workers.
} 
the majority of smallholder farms. More broadly, while previous studies have documented frictions-including separation failures, wage rigidity (Kaur, 2019), and worker collusion (Breza et al., 2019) - they are not designed to tell us whether the magnitudes are ultimately consequential for labor market functioning. Our design is built solely to address this question, offering the first evidence that the labor market is, at times, severely distorted.

At the same time, our finding of instantaneous adjustment in peak months supports the view that spot labor markets can be quite flexible - consistent with studies showing robust labor market adjustment to shocks (e.g. Rosenzweig, 1988; Jayachandran, 2006; Imbert and Papp, 2015; Donaldson and Keniston, 2016; Akram et al., 2018; Breza and Kinnan, 2018; Muralidharan et al., 2020; Egger et al., 2019). Our results therefore reconcile these studies with those above, providing a more complete characterization of labor market functioning.

Our methodological approach also contributes to the literature on measuring unemployment and labor market slack. To date, economists have measured involuntary unemployment using survey self-reports, whose reliability is difficult to ascertain (e.g. Bound et al., 2001; Taylor, 2008; Card, 2011; Faberman and Rajan, 2020). We stack survey responses against our revealed preference findings, documenting the unreliability of such measures. We highlight this can be particularly problematic when rationed workers are likely to switch to other activities, such as self-employment or gig economy jobs. In addition, we build on previous work, which has documented heterogeneity in employment crowd-out from shocks (e.g. Crépon et al., 2013; Gautier et al., 2018). Through precise information on the shock size and by sampling outcomes for the entire labor force, we provide the first revealed preference estimates for the extent of rationing in the economy in any setting.

Finally, our research design provides a cleaner test of excess labor supply relative to other potential approaches, such as offering jobs to the unemployed. In practice, the implementation of this approach has not provided a straightforward test. For example, in Breza et al. (2019), employers are compensated to offer jobs, search costs are eliminated, and the match to workers is randomly assigned. Consequently, it is unclear whether either of the two criteria for rationing is satisfied, making it impossible to quantify rationing. ${ }^{8}$ In addition, our design enables a fuller picture of excess supply and its implications, including the essential role of seasonality, effects on self-employment, and private-sector crowd-out - which requires examining the interaction of labor supply and demand in equilibrium.

Our findings have broad implications for labor market analysis and policy. First, the absence of lean-season market clearing implies that the wage does not always play an allocative role. Thus, analyses that use wages to infer the marginal product of labor, for example, may

${ }^{8}$ Specifically, workers who accepted jobs may not be considered qualified by employers in the absence of the wage subsidy, and may not have preferred the job under natural search and matching conditions. 
be misleading. Second, our findings are relevant for predicting the effects of labor market programs, such as workfare (Imbert and Papp, 2015; Beegle et al., 2017; Bertrand et al., 2017; Zimmermann, 2020; Muralidharan et al., 2020). Specifically, heterogeneity in slack may help explain why some programs have substantive labor market impacts while others have virtually none. ${ }^{9}$ Finally, our finding of large quantities of "forced entrepreneurship" can help explain why policies that direct resources to small firms have only had limited success for the average firm (e.g., McKenzie and Woodruff, 2014; Banerjee et al., 2015).

The remainder of the paper is organized as follows. Section 2 describes the context. Section 3 outlines our hypotheses and predictions. Section 4 details the implementation and Section 5 describes the data. We present the results in Sections 6 and 7. Section 8 discusses microfoundations and potential threats to validity. Section 9 offers suggestive extensions, such as heterogeneity in the impact of India's workfare program. Section 10 concludes.

\section{Context}

Our field experiment takes place in villages across five districts in rural Odisha, India. Markets for casual daily labor are extremely active in our setting specifically, and constitute an employment channel for hundreds of millions of workers in India more generally (National Sample Survey, 2010). The village constitutes a prominent boundary for the casual labor market - daily-wage workers typically find jobs in both agriculture and non-agriculture within or close to their own village. This local nature of hiring is a necessary condition for our experimental hiring shocks to have a meaningful impact on the aggregate labor supply facing firms and on the labor market equilibrium.

The casual labor markets in the study areas are characterized by the same decentralization and informality as much of India (e.g. Rosenzweig, 1988; Dreze et al., 1986). Contracting is usually bilaterally arranged between employers and workers a few days before the start of work. Moreover, the typical job lasts 1-3 days. This short duration of employment contracts creates the potential for transitory labor supply shocks to quickly impact wages. Labor demand is typically infrequent and variable. As in much of India, agricultural labor demand is seasonal, and both agricultural and non-agricultural jobs tend to be task-based (Foster and Rosenzweig, 2017). For example, an employer might hire a different group of 5 workers to weed his paddy fields once or twice in a season, or a skilled roof-thatcher may hire a different assistant each time he is hired to rethatch a roof in the village.

Hiring is also employer-directed. $98 \%$ of agricultural employers report typically approaching workers, by physically going to the neighborhoods where workers live, to fill hiring needs.

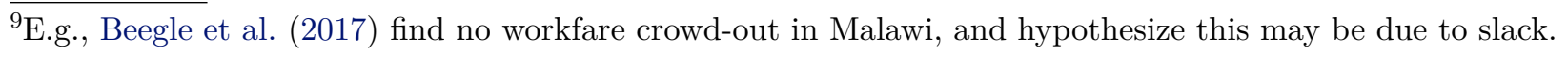


Given the intermittent nature of an individual employer's labor demand, a typical agricultural employer in our sample only hires workers for six days per month. Thus, workers work for many different employers, and each employer works with many different workers. Because rural villages tend to be relatively small and engage in labor relationships every year, employers and workers within a village tend to know one another. For example, when asked to rate the quality of workers in the village, surveyed employers reported not knowing a randomly-chosen worker only $27.9 \%$ of the time. In addition, non-agricultural employers also recruit by driving into the village and picking up workers who are available at the time in trucks. ${ }^{10}$

In our context, labor markets are not fully integrated spatially. For example, employers must pay higher wages to workers who are hired from outside their village, in part due to transportation costs and commuting time. In our data, this amounts to a $12 \%$ wage premium. In addition, workers believe their village-level collective labor supply decisions affect village wages (Breza et al., 2019). This would not be possible under fully integrated markets.

Consistent with the seasonal, project-based nature of labor demand, employment rates in the casual labor market are highly variable, higher in "peak" months and lower in "lean" months. Wage employment rates fall by more than $40 \%$ from peak to lean months. The villages in our study match a general feature of village economies: large periods of low employment (Muralidharan et al., 2020; Dreze et al., 1986).

Self-employment is extremely common in our setting. Among the workers who sign up for the external jobs that form the basis of our hiring shock, $67 \%$ own land, while $88 \%$ have some kind of household business. Common household businesses reported in our context include grocery store owners, street vendors, vegetable sellers and firewood collectors. However, businesses tend to have low levels of capital and small land-holdings, especially for those cultivators who are also engaged in casual labor.

We also note that while India has a well-known workfare program, the National Rural Employment Guarantee Act (NREGA), it is not very well implemented in Odisha. In principle, NREGA offers 100 days of employment in public works annually, but the average employment rate in public works in our sample is $0.5 \% .^{11}$

\footnotetext{
${ }^{10}$ Workers also obtain non-agricultural work by commuting to district towns, though this is less common in our specific context.

${ }^{11}$ In their analysis of NREGA, Imbert and Papp (2015) discuss the vast heterogeneity in program implementation across India; Odisha is notably absent from their list of high-performing states. Moreover, in the NSS data used by Imbert and Papp (2015), respondents in our 5 study districts (2 of which were early program districts), reported zero days of public works employment. Our more recent survey data indicate that the state's implementation issues have persisted.
} 
Finally, in Table 1, we use data from the 2011 Indian Census to show how our study villages compare to the average village in the five districts in Odisha where the experiment was run. The study villages are slightly smaller than average, with 148 households per village in the sample, compared to 176 households overall ( $\mathrm{p}$-val=0.299). However, our sample villages are comparable on most dimensions. For example, $67.8 \%$ of residents are literate in our sample compared to $66.1 \%$ overall ( $\mathrm{p}$-val=0.428), and $74.5 \%$ of males participate in the labor market in our sample compared to $76.9 \%$ across all villages ( $\mathrm{p}$-val=0.306).

\section{Hypotheses}

3.1. Definition of Labor Rationing. Suppose the prevailing wage for one day of work in the casual daily market is $w .^{12}$ We define a worker as rationed on a given day when the following two conditions hold: (i) The worker wants to supply labor at wage $w$, but is unable to find employment; (ii) The worker is qualified for jobs occupied by other villagers.

The first condition states that the worker is not on her labor supply curve. The second condition states that a worker who wants a job but is unqualified for it (in the sense that an employer would never find it profitable to hire her at wage $w$ ) is not considered rationed. Note that this takes no stance on the micro-foundation for rationing.

3.2. Predicted Impacts of a Hiring Shock. The core of our design is an experimental hiring shock, through which a (random) subset of workers in the local labor market is hired in external jobs outside the village. To diagnose rationing, we examine the effects of this shock on local wages and employment - i.e., wages and employment in the local labor market, excluding the external worksite jobs we create.

We model the experimental hiring shock as a supply shock to the local labor market. Through our intervention, some workers are "removed" and placed in external jobsites. This constitutes a reduction in the residual labor supply available to employers in the village; in other words, the (residual) village labor supply curve shifts to the left. However, this modeling choice is not consequential for our test. As we discuss below, we could model this as a demand shock instead and would arrive at the exact same predictions for local wages and employment under rationing. ${ }^{13}$

To lay out our predictions, we employ the simplest framework to interpret our results: a stylized demand and supply framework. Panel A of Figure 1 shows the effects of a negative labor supply shock under market clearing. Let $E$ denote the level of local employment (in

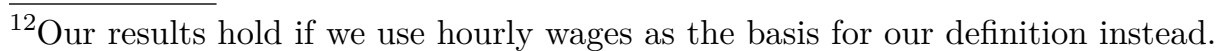

${ }^{13}$ Under the typical definition of a demand shock, we would have posted the jobs, and then, as price takers, hired workers at whatever equilibrium wage prevailed after posting. Instead, we purposely choose which workers to "remove" at a pre-determined (high) wage. This parallels, e.g., workfare programs, which are also typically modeled as supply shocks to the local private sector.
} 
terms of worker-days) in the village and $w$ denote the village wage in the absence of our intervention. A supply shock (a shift from $S$ to $S^{\prime}$ ) will:

P1) Increase local wages from $w$ to $w^{\prime}$;

P2) Decrease aggregate employment among workers who remain in the village (i.e. those who are not hired by us to work in jobsites), so that total employment after the shock $E^{\prime}$ is less than $E$.

Panel B of Figure 1 shows the effects of a negative labor supply shock when there is excess labor supply. As before, $E$ denotes the level of employment in the village and $w$ denotes the village wage in the absence of our intervention. Rationing exists in this labor market, with supply $E_{S}$ exceeding demand $E_{D}$ at wage $w$. Employment levels are therefore determined by the labor demand curve. If the amount of labor rationing is weakly greater than the size of the supply shock, then we predict that the shock (a shift from $S$ to $S^{\prime}$ ) will have:

L1) No effect on local wages (the wage remains $w$ );

L2) No effect on aggregate employment levels (aggregate employment remains E);

L3) Positive employment spillovers on individual workers, whose employment goes up due to reduced competition for job slots.

Note that these predictions are not sensitive to whether $S^{\prime}$ is a parallel shift of the supply curve; they hold even if the supply elasticity changes (i.e. due to a non-parallel shift). If predictions L1-L3 hold, the size of our hiring shock is a lower bound on the level of rationing in the economy.

Note that predictions L2 and L3 above are inherently related. Under rationing, workers who would have otherwise been rationed fill in job slots that are now available because many other laborers competing for the same jobs have become employed outside the village. The resultant increase in the proportion of days employed among remaining workers is why aggregate employment remains unchanged. Appendix Figure A.1 validates that predictions L1-L3 hold under rationing if we model the hiring shock as a positive demand shock instead. ${ }^{14}$

This constitutes a revealed preference test for excess labor supply: If predictions L1-L3 hold, workers reveal that they prefer jobs at $w$ over their previous activity (e.g. unemployment or

\footnotetext{
${ }^{14}$ As Appendix Figure A.1 makes clear, we would expect: (i) no change in the wage, and (ii) aggregate employment (including the external hiring shock jobs) would increase one-for-one with the size of the hiring shock - implying no change in aggregate local village employment (i.e. excluding the hiring shock). This corresponds exactly to Predictions L1 and L2, respectively, and L3 follows mechanically from L2.
} 
self-employment), and employers reveal that workers are qualified to be hired for the jobs at $w .^{15}$

To enrich our understanding of labor market functioning, we undertake the above exercise across different months of the year. This is motivated by earlier work in the development labor literature, which argued that seasonality in labor demand is consequential for shaping labor market equilibrium at different times of the year (e.g. Leibenstein, 1957; Dreze and Mukherjee, 1989). Consistent with this work, we hypothesize that the peak season effects of hiring shocks will be closer to those in Panel A of Figure 1, whereas the lean season effects will match those in Panel B.

3.3. Self-employment and Disguised Unemployment. If there is excess supply, rationed individuals may appear as unemployed or may turn to less-productive self-employment as a way to generate income - creating "disguised unemployment" or "forced entrepreneurship" (Singh et al., 1986). For this group, self-employment earnings are below $w$, but above their reservation wage.

Consequently, under rationing, when job slots open up through the hiring shock, a fraction of both unemployed and/or self-employed workers will reveal that they prefer jobs at the prevailing wage $w$ over what they were previously doing. Among business owners, the magnitude of this shift will provide a lower bound on the fraction of self-employed workers who are disguised unemployed. ${ }^{16}$

3.4. Discussion of Predictions. Predictions L1-L3 diagnose rationing, with minimal other assumptions about the labor market. For example, our test does not require assumptions about the equilibrium in the absence of rationing - whether it is fully competitive $\left(E_{D}=E_{S}\right)$ or subject to monopsony or some other friction $\left(E_{D}>E_{S}\right)$. For example, if there were monopsony in the labor market but no rationing, then our hiring shock would necessarily lead to an increase in wages — contradicting prediction L1 (see Appendix Figure A.2). ${ }^{17}$

\footnotetext{
${ }^{15}$ To illustrate these predictions, consider the following thought exercise. Suppose 10 workers want work in the village at wage $w$, but only 5 job slots are available. As a result, 5 workers are employed at $w$, while the other 5 workers are rationed: the employment rate is $50 \%$. Now, suppose we remove 4 workers from the village labor market. This frees up job slots, and a larger portion of the remaining workers can now work in the village at wage $w$. Specifically, there are 6 workers left who want work and still 5 available slots: the employment rate is now $83 \%$. In contrast, if the 5 workers who are unemployed did not want work, they would not accept employment at wage $w$; this provides a test of condition (i) in the rationing definition above. In addition, the fact that workers who remain in the village are hired at wage $w$ indicates that employers perceive them as qualified for work at $w$; this provides a test of condition (ii) above.

${ }^{16}$ Since we do not take a stance on the rationing mechanism, we do not have an ex ante prediction on whether unemployed or self-employed workers are more likely to be hired into empty job slots first. In addition, if there are fixed costs of stopping and then going back to one's business, then this is another reason why the estimates from this exercise will be a lower bound on disguised unemployment.

${ }^{17}$ If our hiring shock simply shifts the labor supply curve to the left, then the predictions under monopsony are unambiguous - wages should rise and employment should fall. However, if the shock also changes the
} 
In addition, we do not take a specific stance on the reason for rationing; our test is valid for a range of microfoundations. Overall, our test is chiefly powered to detect rationing that is generated by some failure of wage adjustment to seasonal reductions in labor demand. Rationing from effort efficiency wages (Shapiro and Stiglitz, 1984), for example, would not generate the patterns we hypothesize. There, wages would respond to a reduction in labor supply: because the hiring shock would lower the cost of unemployment, wages would need to increase to restore incentives. Section 8.1 discusses microfoundations in light of our results.

We also do not need to specify the rationing mechanism i.e. how jobs are allocated across workers. There may be a distribution of ability levels among rationed workers, and this distribution could even change with the shock. However, if we observe predictions L1 and L3, it must be the case that there are workers in the village who prefer wage jobs and employers are willing to hire them for those jobs at the prevailing wage $w$-satisfying the two criteria in the definition for rationing.

Note that a key feature of our research design is that we can precisely quantify what fraction of the labor force is "removed" through the hiring shock because our shocks are targeted available only to some workers who are offered the external jobs (see below). This stands in contrast to other labor market shocks such as workfare programs, which are permanent and impact all eligible workers by offering an outside option. This potentially increases reservation wages and shifts the labor supply curve even among workers who do not ever participate directly, making it difficult to know what fraction of workers is affected. Consequently, it would be difficult to use a shock such as a workfare policy to quantify rationing. Our transitory targeted shocks greatly simplify analysis, enabling us to bound the level of rationing without needing to impose assumptions about labor supply responses.

\section{Experiment: Design and Implementation}

We engineer transitory hiring shocks in study villages. We exploit an opportunity to recruit casual male workers for full-time manufacturing jobs for 2-4 weeks. ${ }^{18}$ The work occurs in external jobsites within daily commuting distance from study villages. ${ }^{19}$ Such temporary one-time contract jobs are a common source of non-agricultural employment for men in the region. The external jobs are attractive - the daily wage is weakly higher than the prevailing market wage for casual labor, and there are positive compensating differentials (e.g., the work

labor supply elasticity facing the employer, then wages would still increase, but the employment effect is ambiguous. One example is the canonical case of an increase in the minimum wage. See Chapter 2 of Manning (2013) for a detailed discussion.

${ }^{18}$ In this cultural context, women are unwilling or unable to travel outside of the village for work.

${ }^{19}$ We leverage two separate field projects (Breza et al., 2018; Kaur et al., 2019) that involve hiring workers for low-skill manufacturing jobs. See Appendix C for a full description of these jobs. 
occurs indoors and is not very physically demanding). This offers an advantage because it draws interest from many workers in the village, enabling us to (randomly) draw from a sizable swath of the labor force.

The external jobs are advertised in villages through flyers, village meetings, and door-to-door visits to male adults. Hired workers are then drawn randomly from the subset of the village labor force that signs up for the job. See Appendix C for more details about the recruitment protocols and external jobs.

We randomize recruitment intensity at the village (i.e. local labor market) level, so that in treatment villages we hire up to $60 \%$ of sign ups, and in control villages we hire 1-5 workers only. ${ }^{20}$ We thus generate a large hiring shock in treatment villages, and a negligible shock in control villages. We use a matched-pair, stratified research design, so as to achieve balance by local region and time.

We implement these shocks in different months of the year, which correspond to different levels of labor demand and employment. We limited our experiment to ten months of the calendar year, omitting the two busiest months-August (peak planting) and December (harvesting) — so as to not affect labor supply during important work periods. Thus, our experiment does not run in the pure peak season, but rather in the lean and semi-peak (or shoulder) months.

We use employment rates in control villages as our proxy for underlying labor market slack. Months with above-median employment rates are classified as semi-peak periods, while months with below-median employment rates are classified as lean periods of the year.

We run the experiment in 60 villages (labor markets) across 5 districts in Odisha, India, between the years 2014 to 2018 . We used a matched-pair randomization design, so we have 30 treatment and 30 control villages. $43 \%$ of the experimental rounds were conducted in lean months, and the remaining $57 \%$ in semi-peak months. We have survey data for 2,379 workers in total.

Our experiment only has power to detect rationing if the labor market is not fully integrated across villages - so that removing workers in one village constitutes a meaningful local supply shock from employers' perspective. Under full labor market integration, we would not

\footnotetext{
${ }^{20}$ We set this limit of $60 \%$ in order to ensure there were enough workers left over in the village to comprise a substantive spillover sample (on whom we could observe treatment effects), and to avoid the possibility that the shock ended up being larger than the amount of rationing in lean seasons. In addition, we hired no more than approximately 30 workers per village due to space constraints at the external worksites. Note that workers were told in advance that the number of job slots would be determined based on contractor needs, so that ex ante beliefs about hiring probability were the same across treatment and control villages.
} 
expect to find wage adjustment from our hiring shock in either the lean or semi-peak season. Moreover, even in the presence of rationing, we would not detect employment spillovers.

The lack of full integration is a reasonable assumption in our context. Agricultural hiring occurs primarily within the village, as described in Section 2 above. In addition, even for non-agricultural jobs, it is common for contractors to recruit by coming to a village and loading (a predetermined number of) workers onto a truck - providing scope for employment spillovers even for jobs conducted outside the village.

\section{EMpirical Strategy AND DAtA}

5.1. Analysis Samples. Figure 2 summarizes the analysis samples across control villages (Panel A) and treatment villages (Panel B). The dark grey areas denote workers who sign up for the jobs and are "removed" to work in the external jobsites. The light grey shaded areas denote workers who sign up but are not offered jobs - these workers remain in the village and constitute our intent-to-treat sample. We refer to these workers hereafter as the spillover sample. Note that the spillover sample is larger in control villages (Panel A), since only 1-5 workers are offered jobs in control villages.

For the analysis, we examine effects on two sets of samples. The first is the spillover sample, which is directly comparable to the workers who were removed from the village, and therefore would be most likely to benefit from employment spillovers. The second is all potential workers in the village - regardless of whether they signed up for our jobs - in order to accurately assess effects on aggregate employment levels.

5.2. Estimation Strategy. To test how the experimental hiring shock impacts employment and wages, we compare outcomes in treatment and control villages, separately for semi-peak and lean months. Our base specification is:

$$
y_{i t v r}=\alpha+\beta \text { HiringShock }_{v}+\gamma \text { HiringShock }_{v} * \text { SemiPeak }_{r}+\rho_{r}+\bar{X}_{i v r}^{0}+\epsilon_{i t v r}
$$

where $y_{i t v r}$ is an outcome for worker $i$ on day $t$ in village $v$ and experimental round $r$. HiringShock $_{v}$ is an indicator for treatment villages, and SemiPeak $k_{r}$ is an indicator for experimental rounds conducted in semi-peak months. We include the worker's baseline mean employment rate and mean daily wage levels $\bar{X}_{i v r}^{0}$ in order to increase precision (and we also report estimates without baseline controls). Regressions always include round (strata) fixed effects $\left(\rho_{r}\right)$, and cluster standard errors by village.

To construct the SemiPeak indicator, we calculate the mean month-wise employment rate in control villages for each month in our sample, averaging across all rounds that started in a given month (See Appendix Figure A.3). We then take the median of this variable across 
rounds in the sample. Months with above-median values are classified as semi-peak periods of the year. In addition, in the analysis, we show robustness to replacing the SemiPeak binary variable with the continuous month-wise employment rate in the interaction with HiringShock .

Regressions using the spillover sample are unweighted because we survey $100 \%$ of spillover workers. Regressions examining effects for all potential workers are weighted by inverse sampling probabilities in order to be representative of the full labor force.

5.3. Data. We survey all workers who sign up for the external job (i.e. the "spillover sample"). In addition, we survey a random sample of non-signups: prime-age males who work in any capacity - the casual labor market, self-employment or salaried work - since exante we cannot distinguish who among these may potentially be interested in local wage work. We refer to these non-signups plus those who signed up as "all potential workers", and use this sample when testing how the shock affected the entire village labor market. We conduct three waves of surveys: at baseline (immediately before workers are hired at the external jobsites), at endline (during the last two weeks of the hiring shock), and at post-intervention (two weeks after the end of the hiring shock, after all workers are back in the village labor force).

Each survey includes a detailed daily employment grid, in which workers describe their employment activity separately for each day over a recall period, which was either 7, 10, or 14 days (see Appendix C). This includes rich data about wages: cash wages, details of in-kind payments (e.g. tea, meals, and cash value of in-kind payments), whether the worker was paid on time, etc. In addition, it includes detailed characteristics about employment status (activity, length of breaks, hours worked, location) and self-reports of involuntary unemployment for each day. This provides us with the core data needed to test the predictions outlined in Section 3.2.

In addition to the worker surveys, we survey a subset of agricultural employers in the village at endline. ${ }^{21}$ We discuss details in Appendix C.

5.4. Descriptive Statistics. Table 2 presents descriptive statistics and tests of balance across treatment and control villages. Panel A presents characteristics for workers in the main analysis sample (i.e. the spillover sample) drawn from the baseline survey. Panel B presents village-level information. We show means and standard deviations for each covariate

\footnotetext{
${ }^{21}$ In each village, we consulted a village resident to obtain a (partial) list of employers, and surveyed these in random order until we reached 20 employers. While this sample is not necessarily representative of all employers, it can be used as supplementary data to check qualitative patterns, as well as what happens to wages, given strong norms wherein employers pay workers the same wage within the village (Breza et al., 2018).
} 
in control villages and coefficients and standard errors from a comparison of means across treatment and control villages, obtained using a simple univariate regression with round (strata) fixed effects. As expected, given randomization, the groups are well-balanced on covariates.

Consistent with the characterization of the empirical context in Section 2, wage employment rates are low, and self-employment is common among the workers in the spillover sample. On average, respondents report some work on $36 \%$ of the recall period of 10 days - including wage employment on $18 \%$ of the days, and self-employment on $12 \%$ of days. However, respondents report wanting wage work on only 18 days per month (i.e. $60 \%$ of days) on average - a proxy for full employment in our sample based on worker preferences. This suggests that, scaling by this number, workers are employed in wage employment $.18 / .60=$ $30 \%$ of the time that they would like. Our employment rate estimates match those in other parts of India. For example, Muralidharan et al. (2020) report an average employment rate in any private work (wage employment + self-employment) of 7.1 days per month, or $24 \%$, among their respondents in Andhra Pradesh in June. In the Odishan villages surveyed in the Rural Economic and Demographic Survey (REDS), prime age males with small landholdings are employed in wage labor $22.9 \%$ of the time in the lean season. ${ }^{22}$

Appendix Table B.3 presents descriptive statistics comparing those who signed up for the external jobs with those who did not. As expected, those who did not sign up are less likely to be in the labor force: they are 15-22 percentage points less likely to ever participate in the casual labor market and have lower desired labor supply for wage labor. Consistent with this, non-signups are likely to be wealthier-for example, they are less likely to be landless.

At endline, we manage to survey $90 \%$ of spillover sample workers. In Appendix Tables B.1 and B.2, we test for differential survey completion among workers in the main spillover and non-signup samples, respectively. We find no evidence of differential survey attrition rates by treatment assignment. Finally, in Appendix Table B.13, we present descriptive statistics and balance for the employer survey.

\section{Results I: Test for Rationing}

6.1. Size of the Shock. On average, $42 \%$ of potential workers in the village sign up for our external jobs (Table 2, Panel B). Even among workers who actively participate in the casual labor market, one would not expect a 100\% sign up rate for the external jobs. Over $85 \%$ have a household business, which may not be feasible to leave for a one month job. In

${ }^{22}$ Specifically, we consider individuals with less that 1.56 acres, which represents the 90th percentile of landholdings in the spillover sample. 
addition, a job that requires regular attendance and hours may be a disamenity for some workers (e.g. Blattman and Dercon, 2018).

Figure 3 summarizes the size of the hiring shock in treatment villages, measured as the number of workers hired scaled by the size of the labor force of casual male workers in the village. On average, $24 \%$ of the male labor force in treatment villages is hired in the external jobs. In one village, take up is zero as harvesting began early. For the remaining villages, the size of the shock ranges from 15-38\%. Given that the number of workers hired from each treatment village is similar across experimental rounds, the variation in shock size is driven primarily by variation in the size of the male labor force across villages. The average shock size in control villages is $3 \%$.

Further, the size of the hiring shock is indistinguishable in lean and semi-peak months (p$\mathrm{val}=0.792)$. This greatly simplifies the interpretation of our analysis, which compares the effects of the hiring shocks across lean and semi-peak months. ${ }^{23}$

6.2. Wages. We study the impact of the hiring shock on wages in the local labor market (i.e. excluding our external worksite jobs). For each worker-day where the worker reports hired employment for a daily wage, we construct two wage measures: (i) cash wages; and (ii) total wages, which is the sum of cash wages and the monetary value of all in-kind wages (e.g. tea, lunch).

Figure 4 compares the distributions of total wages for treatment and control villages, limiting the sample to lean season observations (panel 1A) and to semi-peak season observations (panel 1B). We cannot reject that the wage distributions in treatment and control villages are equal in the lean months (p-value from a Kolmogorov-Smirnov test is 0.370). In contrast, the wage distribution for treatment villages is shifted to the right relative to the control villages in the semi-peak months $(\mathrm{p}$-val $<0.001)$, indicating a rise in equilibrium wages.

Panel A of Table 3 presents regression estimates for the spillover sample on log cash wages (Col. 1) and log total wages (Cols. 2-3). ${ }^{24}$ At the bottom of the panel, we report the p-value for the F-test of whether the total treatment effect on wages in semi-peak months is significantly different from zero (i.e. $\beta+\gamma=0$ in Equation 1). Note from the control means that wages paid in lean and semi-peak periods are extremely similar. This is consistent with a failure of wage adjustment in the presence of seasonal changes to labor demand.

\footnotetext{
${ }^{23}$ See Table 6 , Col. (4). One might expect the shock size to be weakly smaller in semi-peak months, due to fewer signups when work is locally available. The fact that the worksite jobs were desirable led to ample signups across months. This enabled us to hire enough workers for worksite jobs from among these signups to maintain robust shock sizes across months. Note that if the shock size had been smaller in peak months, this would make it more difficult to find the pattern of our expected results in the reduced form: no wage or aggregate employment effects in lean months, but meaningful effects in peak months.

${ }^{24}$ Wages are winsorized. Appendix Table B.4 documents similar estimates using non-winsorized wages.
} 
Consistent with prediction L1, we find no evidence that wages increase in response to the external hiring shock during lean months. However, during semi-peak months, the hiring shock raises equilibrium wages by $5.0 \%$ (Col. $3, \mathrm{p}$-val=0.026) on average, consistent with prediction P1. The results are similar if we examine effects on wage levels rather than log wages (Col. 4, p-val $=0.047)$.

In Col. (5), we document that the pattern of these findings is similar if we interact the Hiring Shock treatment dummy with a continuous measure of the base employment rate rather than the SemiPeak dummy. Note that the negative coefficients on Hiring Shock in Cols. (5) and (6) do not have a clear interpretation, because there is no month in our data with an employment rate of $0 .{ }^{25}$ Note however, we would expect the effect on wages to be non-linear in the shock size when there is rationing. Under rationing, there would be no change in the wage until the size of the supply shock is greater than the amount of rationing, after which the wage would start increasing in the size of the supply shock. Consequently, we would expect the coefficient on the continuous linear specification to be attenuated relative to the true semi-peak wage effect. While we show the continuous specification for completeness, we primarily focus on the binary specification in the analysis.

In Panel B of Table 3, we present estimates of Equation 1 on the full potential village labor force (i.e. a sample of all village residents). In Cols. (1)-(2), we find that the predictions hold with the full village sample - there is no detectable change in equilibrium wages in treatment villages in lean months ( $\mathrm{p}$-val $=0.680$ and $\mathrm{p}$-val $=0.630$ respectively), and an increase in equilibrium wages in treatment villages in semi-peak months $(\mathrm{p}$-val $<0.001) .{ }^{26}$ In Cols. (3)-(4), we further interact Equation 1 with an indicator for whether the worker signed up for the external job. In treatment villages, equilibrium wages increase in semi-peak months for both sign-ups (Col. 4, p-val=0.012) and non sign-ups (Col. 4, p-val=0.032), and do not change for either group in lean months. ${ }^{27}$ This indicates that the wage results are not driven simply by a compositional change in the labor force. In Cols. (5)-(6), we run a similar analysis using information about cash and total wages reported by a sample of employers. We find quite comparable effects, both qualitatively and quantitatively.

Our primary wage measure is in terms of the daily wage, since this is the most common form of wage contract in these labor markets. In Table 4, we verify that our results are robust

\footnotetext{
${ }^{25}$ The mean lean season employment rate in control villages is 0.145 (reported in Table 5 below). Using the results in Table 3 Col. (5), this corresponds to an estimated wage effect of 0.0043 (s.e. $=0.0204$, p$\mathrm{val}=0.834)$ - consistent with no wage increase in the lean season.

${ }^{26}$ Because we sampled a small share of workers who did not sign up for the outside jobs, these weighted full-village regressions have larger standard errors than those in Panel A.

${ }^{27}$ Note that these results are not powered to detect whether the wage effects on non-signups are different from sign-ups, given the standard errors on the interaction terms. Our goal in this table is to test whether overall wages for non-signups also went up in each season.
} 
to measuring impacts on the hourly wage (rather than the daily wage). In addition, we find little evidence of shifts in other aspects of the wage contract or compensating differentials - for example, the number of hours per workday, or expectation of receiving future benefits from the employer such as work in the future. This helps assuage concerns that the effective wage did increase in the lean season, but through non-price amenities. Moreover, such a story would need to explain why wage levels adjust in semi-peak months but not in lean times.

6.3. Individual-Level Employment Spillovers. To test for positive employment spillovers, we measure effects on the spillover sample. These workers are exactly comparable to those who were "removed", and therefore should benefit from the decreased competition for job slots. We measure effects on all village residents when we examine effects on aggregate employment below.

Table 5 provides estimates of Equation 1. The dependent variable is a dummy for whether worker $i$ was hired to work for someone else on day $t$ in the local labor market for a wage.

Consistent with Prediction L3, in lean months, wage employment increases by 5.44 percentage points $(\mathrm{p}-\mathrm{val}=0.005)$ on a base rate of $0.145(\mathrm{Col} .2)$ - implying a $38 \%$ increase in employment among workers who remain in the village. This is consistent with our prediction that workers who were previously rationed fill in available job slots. In contrast, we cannot reject that there are no employment spillovers in semi-peak months ( $\mathrm{p}$-val=0.427). These patterns are robust to using the continuous employment rate rather than the semi-peak dummy (Col. 3). ${ }^{28}$ Panels $2 \mathrm{~A}$ and $2 \mathrm{~B}$ of Figure 4 verify these patterns visually.

6.4. Aggregate Employment. To test impacts on aggregate employment levels (Predictions L2 and P2), we must measure employment for the entire potential labor force including those who did not sign up for our jobs. We undertake this analysis in Table 6 . We consider all potential workers in the village, which includes our spillover sample, the individuals that were randomly selected to receive external jobs, and a random sample of all other village residents. ${ }^{29}$ The dependent variable is the same as in Table 5: a dummy for whether worker $i$ was hired for paid wage work on day $t$ in the local labor market (i.e. all employment excluding our external worksite jobs).

\footnotetext{
${ }^{28}$ As discussed above, under rationing, employment effects will be non-linear in the size of the hiring shock. One would expect positive employment spillovers in the lean season as long as the shock size is less than the rationing level. Once the shock size exceeds this, and wages begin to rise, the employment effect should be smaller, possibly even becoming negative - a potential non-monotonic effect in shock size.

${ }^{29}$ For those offered the external jobs, they could have worked in the local labor market on days they were not at the external jobsites, such as weekends, absences, or if they quit the worksite job. Note that if some of the employment spillovers accrue to those who did not sign up for jobs, the aggregate employment effect among only the sign-ups could be negative in the lean season, even in the presence of rationing. We consequently include all workers, including non-signups, in this test.
} 
Consistent with prediction L3, there is no detectable change in local aggregate employment in response to an external hiring shock in lean months (Col. 1, p-val=0.628). This follows directly from the results above - because wages and local labor demand remain unchanged, rationed workers fill up the job slots, leading to the same level of aggregate employment. In contrast, in semi-peak months, the hiring shock reduces aggregate employment, consistent with prediction P2. Local employment among all workers declines by 4.3 percentage points overall ( $\mathrm{p}$-val $=0.004$ ) on a base rate of wage employment of 0.195 in semi-peak months. This corresponds to a $22 \%$ decline in aggregate employment. Moreover, this decrease is detectably different from the null result in lean months. Col. (2) shows that these effects are robust to using the continuous employment rate.

This pattern of results is similar if we run the analysis at the village-day level instead (summing up all employment within the village on each day) (Col. 3). Finally, in Panels 3A and 3B of Figure 4, we plot the CDFs showing aggregate employment effects in semi-peak vs. lean times - providing visual verification of these patterns.

6.5. Crowd-Out. The findings in Cols. (1) and (2) of Table 6 help us understand the extent to which an external hiring shock crowds out private wage employment. In the lean season, giving full-time jobs to a quarter of workers generates no crowd-out in the private labor market.

To quantify the crowd out in the semi-peak season, we must scale the employment estimates by the number of worker-days of external work created through our hiring shock. In Cols. (3) to (5) of Table 6, we run village-day level regressions using the hiring shock as an instrument for employment in the external jobsites. Col. (3) presents the reduced-form result of the hiring shock on village employment, constructed by adding up individual employment across all potential workers in the village. Consistent with the worker-day level regression results in Col. (1) of Table 6, we find no change in local aggregate employment in response to the hiring shock in lean months, and a significant decline in semi-peak months. Col. (4) presents the first stage, and shows that a substantial fraction of workers were "removed" into the external job, with no detectable differences in lean versus semi-peak months. The IV estimates in Col. (5) suggest that, in semi-peak months, each day of work that is created in the external jobsites crowds out 0.264 days of private labor market employment (p-val $<0.001){ }^{30}$

6.6. Persistence After the End of the Shock. We survey workers two weeks after the hiring shock ends, when all workers are back in the village, to measure the persistence of the

${ }^{30}$ In contrast, the estimate for lean months is much smaller in magnitude and noisily estimated ( $\mathrm{p}$-val=0.767), implying that external jobs generate no detectable crowd-out in the private labor market in the lean season. This is consistent with the reduced form results in the first two columns of Table 6 . 
shock in both lean and semi-peak periods. Table 7 presents estimates of Equation 1 for our main wage and employment outcomes using this post-shock data. Cols. (1)-(3) document that the lean season spillover effects are transitory - lasting only as long as the hiring shocks do. Once the shock ends and all workers are back in the village labor force, we see no more employment spillovers and there remains no detectable difference in treatment and control village wages. This is what one would expect if the initial response to our hiring shock was due to rationing. ${ }^{31}$ It also rules out, for example, a wealth or aggregate demand effect explanation for our lean season results (see Section 8 below).

In contrast, also consistent with excess labor supply, the semi-peak season hiring shocks do have persistent effects. After wages go up, they do not adjust back down after the transitory shock ends, leading to a drop in employment - consistent with a ratcheting effect from downward wage rigidity (Kaur, 2019). These results point to a dynamic inefficiency in labor market adjustment.

\section{Results II: Rationing Implications}

7.1. Self-Employment and Separation Failures. A worker who is rationed out of wage labor may remain involuntarily unemployed or engage in a productive activity such as selfemployment to earn at least some money. In our setting, recall that $88 \%$ of workers in the spillover sample report some form of self-employment at baseline, ranging from farming to non-agricultural activities such as food preparation or selling firewood.

During the lean season, when job slots open up under the hiring shock, workers have the option to switch from self-employment to wage employment at the prevailing wage. Such a switch would indicate that these self-employed workers were rationed: they prefer wage employment over what they were previously doing. Switching between self- and wage employment is plausible in our context because the vast majority of individuals with a business participate actively in the casual labor market. $72 \%$ of those with a household business in the spillover sample report casual labor as their primary occupation and an additional $24 \%$ report casual labor as their secondary occupation.

We test for this pattern in Table 8. In lean months, the hiring shock leads to a 3.4 percentage point $(24 \%)$ decline in self-employment days (Col. 1, p-val=0.088). ${ }^{32}$ This implies that in the spillover sample, at least $24 \%$ of lean season self-employment stems from workers being

\footnotetext{
${ }^{31}$ In some earlier rounds, follow-up surveys were implemented with longer lags. The results in Table 7 are robust to restricting to rounds where follow-up surveys were within a month of the end of the hiring shock. In addition, note that changes in mean control group employment rates between the endline and follow-up surveys are not statistically different from each other.

${ }^{32}$ This effect is more precise when we restrict to a smaller recall period of 7 days - corresponding to a $31 \%$ decline ( $\mathrm{p}$-val=0.004) - consistent with less measurement error (see Appendix Table B.5). In addition, in Appendix Table B.6, we document that if we examine effects on hours of self-employment rather than days,
} 
rationed out of wage work. This is likely a lower bound, both because our test is constructed as such, and additionally because there may be fixed costs of switching from self-employment to wage employment for a short duration of time. This reduction in self-employment accounts for $62 \%$ of the employment spillovers documented in Table 5 above. Note that there is no clear prediction on what should happen to self-employment in semi-peak months, since the wage has gone up. ${ }^{33}$

Note that similar to the employment spillovers, the lean season effects on self-employment are also transitory. Once the hiring shock ends, self-employment levels between treatment and control villages are indistinguishable (documented above in Table 7, Col. 4). This rules out the concern that our self-employment results simply reflect inter-temporal substitution; under this explanation, there should be an increase in self-employment in the 2-week follow-up after the shock ends. If anything, there is a persistent decline in self-employment, potentially reflecting fixed costs.

In Table 8, Cols. (2) and (3) decompose the self-employment effects during the hiring shock. Non-agricultural self-employment declines by 3.3 percentage points, corresponding to a stark $50 \%$ decrease relative to the control group mean for small landholders (Col. 2). This is consistent with the fact that most non-agricultural businesses in our sample have no fixed assets, and a large fraction shut down in semi-peak months. Similarly, agricultural selfemployment goes down by 3.0 percentage points, but this average effect is not statistically significant (Col. 3, p-val=0.193). ${ }^{34}$

Among farm households, a ration in the labor market is most likely to distort employment when landholdings are small (relative to the number of adult workers in the household) because the household's own farm will not be able to absorb all its labor. ${ }^{35}$ This is the key prediction that is usually tested in the separation failures literature. Consistent with this, we find that the decline in agricultural self-employment is concentrated among households

results are similar although noisier, consistent with difficulty in recall of self-employment hours (Arthi et al., 2018).

${ }^{33}$ This increases the opportunity cost of self-employment, and so could decrease own business work. Alternately, this could also lead to an increase in self-employment - either to equate the shadow wage of self-employment with external wage work, or if smallholder farm households are liquidity constrained in their ability to pay for wage labor. The results indicate that on average, self-employment also declines in semi-peak months.

${ }^{34}$ The analysis on agricultural work restricts to rounds where at least one person in the control village reports working at least one day on his farm. This drops 5 rounds from the estimates. Having zero agricultural work among all respondents indicates that the region is one where agriculture is non-existent, or that the lean season production function is such that there is literally nothing to do on the land.

${ }^{35}$ This is closely related to the ubiquitous observation that smaller farms tend to use more labor per acre than larger farms (e.g. Sen, 1962; Bardhan, 1973; Barrett, 1996; Foster and Rosenzweig, 2017). We find this relationship in our baseline data as well (Appendix Figure A.4). See Gollin and Udry (2019) for a discussion of the role of measurement error in interpreting this relationship. 
with below median levels of per capita landholdings (Table 8, Col. 4). Among these small farms, there is a 7.2 percentage point reduction in agricultural self-employment during the lean season (off a base of 14.3 percentage points in control villages). In contrast, we cannot reject there is no change in lean season self-employment among larger farms. In Col. (5), we document that this corresponds to a $43 \%$ reduction in total labor use on the farm - own family labor plus hired labor. This matches the key findings of prior work examining the implications of separation failures (e.g., Benjamin, 1992; Udry, 1996; LaFave and Thomas, 2016; Dillon et al., 2019; Jones et al., 2020; Kaur, 2019). Moreover, we trace a direct link from labor rationing to separation failures. Our findings imply that among small farms in lean months, $50 \%$ of self-employment is driven by rationing. These workers would prefer to divert the majority of their farm-work time to wage labor at the prevailing wage if jobs were available.

If workers switch to wage work, other family members may substitute into working on the family enterprise. While this in itself would not undermine our interpretation of rationing, in Col. (6), we empirically examine the effect of the hiring shock on total household selfemployment across all adult members. Consistent with the results in Col. (1), total household self-employment declines by $33 \%$ in lean months $(\mathrm{p}$-val $=0.012)$. In Col. $(7)$, we repeat this analysis for the all potential workers sample, with similar results: a $38 \%$ decline (p$\mathrm{val}=0.085)$. We repeat the analysis from Cols. (3)-(5) for all potential workers in Appendix Table B.7. Overall, our findings indicate that the hiring shock leads to a sizable aggregate decline in self-employment across the village as a whole in lean months.

7.2. Measuring Involuntary Unemployment in Surveys. In Table 9, we examine survey-based measures of unemployment status. In Cols. (1) and (2), we first begin by testing the effect of the hiring shocks on an indicator for whether worker $i$ did any private sector work on day $t$ in the local labor market (wage employment or self-employment). There is no detectable change in overall reported work status. This is consistent with "disguised unemployment" - because rationed workers had switched to other work activities, the hiring shocks in lean months appear inconsequential.

Next, we assess the traditional measure for involuntary unemployment used in surveys. This lists "would have liked to work but was unable to find any" as one of the options for the activity for that day. Workers can choose this option if they do not report having work in some other activity. This is how involuntary unemployment is measured in virtually all surveys, from India's National Sample Survey to Labor Bureau surveys in the US. However, when there is disguised unemployment — such that self-employment masks rationing these measures would not accurately reflect labor market slack. Consistent with this, in Cols. (3) and (4), we cannot detect an effect of the hiring shocks on lean month involuntary 
unemployment: the coefficient is negative but insignificant ( $\mathrm{p}$-val $=0.173$ and $\mathrm{p}$-val $=0.242$ respectively).

To address this challenge, we wrote an alternate survey question which asks workers to state whether they would have accepted a job at the prevailing wage that day over whatever else they had been doing (i.e., even if they were self-employed). Consequently, it should be less sensitive to the presence of disguised unemployment. The exact phrasing of this question was: "Suppose someone offered you work at the prevailing wage in your village on this day. Would you have accepted the work?" To denote the "prevailing wage", we used the phrase in the local language (Odiya) that denotes the standard going rate for a day of agricultural work in the village. Using this measure, the hiring shocks reduce involuntary unemployment by 7.0 percentage points in the lean season (Col. 5, p-val=0.008). This magnitude closely matches the size of the revealed preference response from our employment spillover effects (see Table 5). Moreover, the lean season estimate in Col. (5) is statistically different from that in Col. (3) ( $\mathrm{p}-\mathrm{val}=0.067)$.

While this alternate question offers benefits over the traditional measure, and its movement contains signal about labor market conditions, it may suffer from its own issues. For example, it could overstate involuntary unemployment if business owners intertemporally substitute self-employment across days. As with any self-reported measure, it could also overestimate slack if workers are hesitant to admit that they are voluntarily unemployed, or searching for an unattainable job. Consistent with such concerns, the means of this variable are unrealistically high. For example, the sum of involuntary unemployment plus wage employment days is greater than workers' self-reported preferred "full-employment" rate of $60 \%$ (see Table 2). Overall, this highlights challenges with using self-reported survey measures.

7.3. Effects on Employers. If there is severe rationing in lean months, then removing a quarter of workers may not have any negative consequences on employers in the lean season. We examine this idea using proxies from an employer survey conducted at endline in Appendix Table B.8. In lean months, the hiring shocks, do not negatively disrupt agricultural work (Cols. 1 and 2), do not make it harder to find workers (Cols. 3 and 4), and do not change the perceived quality of workers (Col. 5).

In contrast, in semi-peak months, the hiring shocks appear to negatively impact employers using these proxies. Employers are 6.4 percentage points more likely to have to resort to hiring workers from outside the village, an $82 \%$ increase relative to the control mean (Panel B Col. 3, p-val <0.001). The results also suggest that employers did not undertake as many cultivation activities as they would have liked, or as early as they would have liked (Panel B Cols. $1-2$, p-val $=0.060$ and $\mathrm{p}$-val $=0.082$, respectively). Interestingly, there is some indication 
that in the semi-peak season, the wage increase enables employers to attract better quality workers, as evidenced by employer's ratings of worker quality (Panel A, Col. 5). These results should only be taken as suggestive given that we did not survey a random sample of employers (see footnote 21).

Overall, these patterns are consistent with the idea of "surplus labor" in lean months only. ${ }^{36}$ They match Leibenstein's predictions of "under-utilized labor". In lean times, there exist workers who can be removed from the labor market with little apparent impact. However, in semi-peak times, the marginal product of the marginal worker is meaningfully large.

7.4. Allocation Mechanism. In the presence of rationing, the wage no longer plays an allocative role - raising the question of the rationing mechanism: are higher ability workers hired first, or are job slots randomly assigned? In our setting, queuing by ability is possible for hiring within the village for agricultural work (since farmers know the workers) but less likely for casual work in the non-agricultural sector (where contractors come to villages to load workers onto trucks in a more arms-length fashion) (see Section 2). If higher ability workers are hired first, then the employment spillovers we document should accrue to less able workers, who would be next in line for jobs.

We empirically investigate this in Appendix Table B.9 by examining heterogeneous treatment effects by commonly used proxies for worker ability. In Col. (1), we find little evidence that in lean months, spillover effects accrue to workers who receive worse baseline ability ratings from employers in the village. In Col. (2), we do see suggestive evidence that those with higher baseline employment are less likely to benefit from employment spillovers: a one standard deviation increase in baseline employment rate is associated with a 4.41 percentage point reduction in the hiring shock treatment effect in the lean season, but the coefficient is insignificant ( $\mathrm{p}$-val=0.149). In Col. (3), we find no detectable differences in employment spillovers by baseline wages. However, in our context, wages are unlikely to convey information about worker ability because casual wages are compressed-limiting the scope for any differential impacts (e.g. Breza et al., 2018). Overall, these findings do not offer conclusive evidence on whether there is queuing by ability - an interesting topic for future research.

The allocation mechanism is potentially consequential for employer surplus. Removing workers from the labor force will have no effect on employer profits under random rationing, but may decrease profits under queuing if enough high ability workers are removed. Note that this does not alter the interpretation of the amount of rationing detected by our hiring shocks: in both cases unemployed workers' marginal product is above the prevailing wage,

\footnotetext{
${ }^{36} \mathrm{~A}$ crisper test of the surplus labor hypothesis would entail measuring impacts on yields or profits. However,
} since our shocks lasted as little as 2-3 weeks in some rounds, this would be an under-powered test. 
in line with the definition of rationing (see Section 8.2 below). In addition, if workers are heterogeneous in ability, this would imply that one can remove the lowest ability workers (whose marginal product may still be above the prevailing wage) in lean months without any change in output - a more nuanced interpretation of the idea of "under-utilized labor".

\section{Discussion: Potential Microfoundations and Threats to Validity}

We next turn to two important discussions. First, we consider possible microfoundations that could give rise to excess labor supply. This is important because many questions of efficiency and welfare depend on understanding why the labor market looks this way. Second, we consider several potential threats to validity that could, in principle, confound the interpretation of our results.

8.1. Potential Microfoundations. We examine possible microfoundations for rationing in light of our results. The canonical moral hazard efficiency wage model (Shapiro and Stiglitz, 1984) produces involuntary unemployment in equilibrium. However, this model would predict that our hiring shocks would increase wages to maintain equilibrium unemployment to restore incentives. ${ }^{37}$ It is also unclear why rationing would exist differentially in lean months relative to semi-peak ones. Nutrition efficiency wages can also generate involuntary unemployment (Dasgupta and Ray, 1986). However, in semi-peak months, our finding of a ratcheting effect - wages remain higher even after the transitory hiring shock ends - is inconsistent with a nutrition efficiency wage, since wages should be able to fall back down to their pre-shock levels if the wage floor was based on the cost of purchasing a certain number of calories. Thus, both of these efficiency wage models are inconsistent with our findings.

In addition, dynamic contracting or implicit insurance models-e.g., in which employers smooth wages for their more risk averse workers across seasons - could generating rationing in some demand states (e.g. Azariadis, 1975; Rosen, 1985). ${ }^{38}$ The most straightforward versions of these models should not generate a ratcheting effect on wages, leading to a drop in employment - contradictory to our results. However, our results do not definitively rule out the potential relevance of dynamic contracting between workers and employers.

Two other microfoundations are potentially more compatible with our results. First, a feature of workers' preferences may lead them to resist wage cuts (e.g. Keynes, 1937; Akerlof and Yellen, 1990; Fehr et al., 2009). Second, monopoly power on the part of workers could also

\footnotetext{
${ }^{37}$ As we discuss in Section 3.2, our test is not powered to detect rationing from this class of models.

${ }^{38}$ Some versions of these models would imply that while there is rationing, it is not inefficient - the wage is simply not playing an allocative role. Our ratcheting effect suggests that rationing can lead to inefficiencies in employment levels.
} 
generate rationing. In a similar setting, Breza et al. (2019) find evidence that workers behave as an informal union to prop up wages. ${ }^{39}$

Our findings only allow a suggestive glimpse into microfoundations. Ultimately, which microfoundations are responsible for rationing will determine its welfare and efficiency consequences. This provides impetus for future work on micro-foundations.

8.2. Threats to Validity. There are several potential confounds that could give rise to (a subset of) predictions L1-L3 even if there is no rationing. Any alternate explanation would need to explain all three of our lean month findings, and also explain why this confound would only operate in lean months but not peak months (during which we observe drastically different results).

Change in composition of workers. There may be some selection into which workers sign up for the external worksite jobs, potentially changing the composition of workers left behind in treatment villages. If this decreases the average quality of workers in lean months, it could put downward pressure on the wage - counteracting the upward wage pressure from the supply shift, generating no change on average (confounding prediction L1). Note that for this to also generate prediction L3, the demand elasticity would need to be such that employers would still want to hire the same number of workers at $w$, even though worker quality has changed. More directly, in Section 7.3, we show that employer perceptions of worker quality are no different in treatment versus control villages during lean months (Appendix Table B.8 Col. 1). In addition, recall from Section 6.2 that our wage results look very similar among those who signed up for the external job (Table 3 Panel A), and those who did not (Table 3 Panel B).

Note that our test allows for workers to be heterogeneous in ability and for some workers to be unqualified to work at the market wage. Even if the average ability of workers that are left behind did change, this would not confound our test for the level of rationing. By revealed preference, any worker that receives employment spillovers from the hiring shock must be sufficiently productive to be employed at the market wage rate. In other words, what matters for rationing is workers' absolute marginal product level being above $w$.

Wealth and aggregate demand effects. The external jobs created under the hiring shocks generate an infusion of wealth in treatment villages. A potential concern is that this may

\footnotetext{
${ }^{39}$ Work in the development labor literature has documented other frictions that can generate inefficiencies in employment levels - such as information frictions where the employer does not know if the worker is qualified for the job (e.g. Foster and Rosenzweig, 1996; Beaman and Magruder, 2012). The primary microfoundations we consider in this section are based on our definition of rationing. In our test, employers reveal that they consider the worker to be employable at the current wage, suggesting they knew that rationed workers are qualified.
} 
subsequently lead to an expansion of local labor demand, which could counteract the supply shift and subsequently generate no change in aggregate employment (confounding prediction L3). However, if this alternate explanation were true, this should put even more upward pressure on wages, which would be inconsistent with prediction L1.

Results from the 2-week follow-up survey (Table 7, Section 6.6) also help rule out this confound. The laborers hired in the external jobs received their final wage payment on the last day of work. If households began consuming more, we would expect that immediately after the transitory hiring shock ends, there should still be a demand expansion. However, we find that as soon as the transitory shock ends, the labor market returns exactly to where it was before the shock - indicating that any wealth impacts on employment are minimal.

Substitution in work activities across household members. In Appendix Table B.10, we show impacts of the hiring shock on family members of spillover sample workers. ${ }^{40}$ If other household members are also participants in the casual wage market, we should expect their employment to mirror that of our spillover sample: positive employment spillovers and reduction in self-employment in lean months. In Col. (2), we detect positive lean-season hiring spillovers onto the family members that participate in the casual labor market, providing robustness to our main findings. In Col. (5), we find a negative and statistically significant impact of the lean-season hiring shock on self-employment, implying that total work days in household enterprises fall when labor market opportunities improve. This indicates that there is not some substitution in activities across household members driving our results.

Integrated labor markets. If the labor market is integrated across villages, our hiring shock would only constitute a small supply shock to employers - potentially explaining the lack of wage effects in lean months. However, in this case, we should also see no employment spillovers in the lean season. This could also not explain why wages rise in semi-peak months.

Perfectly elastic labor supply. If labor supply is perfectly elastic at the market wage, this could generate predictions L1-L3 even when there is no rationing. Appendix Figure A.5 summarizes results from a labor supply elicitation exercise, conducted in the same districts as our experimental sample. Breza et al. (2019) partner with agricultural employers to randomize individual wage offers to workers in the local labor market. When the wage offer

\footnotetext{
${ }^{40}$ Each spillover sample respondent reported the number of days in the prior week that other adult household members worked in wage employment and self employment.
} 
is reduced from the prevailing wage to a $10 \%$ cut, take-up of the job declines from $26 \%$ to 18\%. ${ }^{41}$ This suggests that labor supply in this setting is far from perfectly elastic.

Power to detect wage increases. Because there is a confidence interval around our wage effect estimates, one potential concern is that in the lean season, there may have been a meaningful wage increase (contradicting L1), but we are under-powered to detect it precisely. We examine this concern by taking the confidence intervals around the wage and employment effects seriously. Suppose the wage increased by the magnitude corresponding to the right side of the wage effect confidence interval: $1.92 \%$, and that aggregate employment does not change. The 95\% confidence interval around the employment spillover effect in lean months is $[.018,0.091]$, corresponding to a percentage increase of $[12.4 \%, 62.6 \%]$. From the perspective of an individual (atomistic, price-taking) worker, this would indicate that seeing a wage increase of $1.92 \%$ led him to increase his labor supply by $12.4-62.6 \%$. The labor supply elasticity required to induce this employment response for an individual worker remaining in the village is in the range of $6.47-32.59 .{ }^{42}$ This is implausibly high and substantively larger than the residual labor supply elasticity estimates derived by Breza et al. (2019) and Goldberg (2016). The aggregate semi-peak labor supply elasticity implied by our experimental results is also much smaller. (See Appendix E.) Such an overly large individual supply elasticity estimate is exactly what one would expect under excess labor supply.

Repeated Contracts and Implicit Insurance. Because workers and employers participate in the same local labor market, there is potential scope for repeated or reciprocal relationships (e.g., Bardhan, 1983; Mukherjee and Ray, 1995; Anderson et al., 2015; Rosen, 1985).

One might worry that repeat relationships might mask wage increases in lean months because employers could compensate workers through other channels such as promises of future work. Such concerns amount to potential mismeasurement of the wage (contradicting L1). However, in Table 4, workers do not report differential expectations of future work between treatment and control villages in either season. Moreover, if these unpriced favors are costly to the employers, then we should also expect aggregate village employment to decrease in treated villages in lean months, which we do not observe empirically.

It might also be the case that workers and employers insure one another against unanticipated labor market shocks, such as the experimentally-induced shock studied here. While possible

\footnotetext{
${ }^{41}$ These estimates use the take-up of jobs under the "private" condition. We view this as reflecting true residual labor supply and offering the best estimate of the residual supply elasticity under a wage increasesince that is the relevant direction for wage changes under our negative supply shock.

${ }^{42}$ For this exercise, we allow for correlation between the wage and employment spillover regressions when calculating the confidence intervals using SUR. If instead, we use the confidence intervals directly from the regressions in Tables 3 and 5 (assuming independence), the implied labor supply range elasticity is 4.82-25.68.
} 
in principle, such an explanation would involve poorer workers providing insurance to the wealthier employers, whereas the literature normally posits insurance flowing the opposite way. In addition, our semi-peak findings would indicate that insurance provision by workers only occurs in lean times - when workers themselves are poorest.

Finally, as we discuss in Section 8.1 above, there is a class of dynamic contracting or implicit insurance models that could generate labor rationing. However, in this case, these would not be a confounding explanation but rather a potential microfoundation for our findings.

\section{EXTENSION: LABOR MARKET SHOCKS AND LABOR MARKET SLACK}

Our experimental results highlight how the same labor supply shock can have dramatically different impacts in periods of high versus low labor market slack. This finding has implications for labor market policies. In Appendix Figure A.6, we document high levels of variation in employment rates across districts in India (Panel A) and across the months of the year (Panel B). The interquartile range of cross-district employment levels spans 0.76 to 2.07 days per week. Moreover, the median state has more than a $100 \%$ employment increase between the month with the lowest versus highest employment rate within the year. If baseline employment rates correlate with labor market slack, then this spatial and temporal variation suggests that the same policy implemented nation-wide and year-long might have heterogenous impacts, absorbing rationed workers in some cases and crowding out private sector employment in others.

In a suggestive exercise, we analyze India's workfare program, the National Rural Employment Guarantee Act (NREGA), through this lens. Like many workfare programs around the world, NREGA guarantees work in public works at a government-mandated wage. While such programs primarily operate during agricultural lean seasons, NREGA does occur throughout the year (Appendix Figure A.7).

We note that our experimental hiring shock is not directly comparable to a workfare policy. Such programs constitute a permanent shock that impacts all eligible workers by offering an outside option. This potentially increases reservation wages and shifts the entire labor supply curve, even among those who never participate in the program. Consequently, such programs are more likely to lead to wage increases than our shock, which was both transitory and available only to the participants we randomly selected.

We examine the phased roll-out of NREGA across districts in India, following Imbert and Papp (2015). Further, we consider differences in the program's impacts by baseline employment levels. We use worker-level employment data from the National Sample Survey (NSS), rounds 61 (July 2004- June 2005) and 64 (July 2007- June 2008). The NREGA phase-in 
began in 2006, and by April 2007, 330 of India's 610 districts had received the program. We estimate the following triple-differences regression:

$$
y_{i d m t}=\beta N R E G A_{d t}+\gamma N R E G A_{d t} \times H i g h_{d m}+\delta H i g h_{d m}+\rho_{d}+\rho_{m t}+\lambda X_{i d m t}+\varepsilon_{i d m t}
$$

where $i$ indexes the individual, $d$ indexes the district, $m$ is calendar month and $t$ is year. $N R E G A_{d t}$ is the program indicator, equal to 1 in districts that had already received the program in round 64 . High $h_{d m}$ is a binary indicator for whether a district x month pair had above-median casual employment (low slack) prior to NREGA, averaging across households surveyed in rounds 60 and $61 .^{43}$ Note that this captures both cross-district spatial variation and within-district seasonal variation in casual employment. $\rho_{d}$ and $\rho_{m t}$ denote district and month-by-year fixed effects. $X_{i d m t}$ is a vector of controls, including worker characteristics by round (gender, education, age), baseline agricultural yields by round, and district-bymonth baseline means of casual employment, wages, and self-employment. We predict that when there is less slack in the labor market, labor market shocks such as NREGA should put more upward pressure on wages, leading to relatively more crowd-out of private sector employment, $\gamma_{w}>0$ and $\gamma_{e}<0 .{ }^{44}$

We view this exercise as merely suggestive because of one important caveat. While the national program phase-in can be taken as quasi-exogneous under the assumptions laid out in Imbert and Papp (2015), the size of the NREGA program in a given district-month is endogenous. Importantly, the demand and supply of NREGA jobs, conditional on having the program, may be directly related to labor market slack at the time. Consequently, we cannot use findings from this analysis to make any strong causal claims.

Appendix Table B.11 presents the results. There is a strong first stage: districts that received the program by 2007 have more employment in public works (Col. 1). If anything, there is more public works in settings with higher baseline employment, though the coefficient is not statistically significant.

Consistent with our predictions, we find that labor market slack mediates NREGA's reduced form impacts. In Col. (2), we find no evidence for NREGA-driven wage increases in places with below-median employment rates. However, the daily wage rises in places with abovemedian employment rates ( $\mathrm{p}$-val=0.014). In Cols. $(3)-(4)$, we find no evidence of private

\footnotetext{
${ }^{43}$ In some cases, the survey months for a district in rounds 60-61 do not overlap with the survey months in round 64 . We thus control for whether the heterogeneity measure is not well defined for a round 64 observation. We code such cases as not having high baseline employment.

${ }^{44}$ We do not have strong predictions on $\beta_{w}$ and beta $a_{e}$ given the size of the NREGA shock and its relevance for the wages of all workers in the labor market.
} 
sector employment crowd-out in district-months with below-median baseline employment. However, NREGA does puts downward pressure on private sector employment in districtmonths with above-median employment. The program crowds out agricultural employment by almost $20 \%$ (p-val=0.031) when the labor market appears tighter. Finally, the program decreases self-employment when there is more slack (Col. 5); consistent with Section 7.1, we observe people switching out of self-employment, despite no change in the wage.

This suggests that programs like NREGA can be implemented with little crowd-out in places and times of year where slack is high. However, when slack is low, the story is different. If the policy goal is to provide work opportunities to rationed workers, then this could be accomplished at substantially lower cost (and reduced private sector crowd-out) by improved geographical and temporal targeting.

\section{Conclusion}

We document the coexistence of two markedly different labor market paradigms. During lean periods, over a quarter of labor supply is rationed, while during semi-peak periods, the labor market adjusts rapidly to shocks. These patterns of seasonality match Leibenstein's predictions of "under-utilized labor." Moreover, during lean periods, we find no evidence of adverse impacts on employers in treated labor markets. Taken at face value, this suggests that workers can be "removed" from the labor market, but only during slack periods. Because semi-peak season aggregate employment does decrease in response to a labor supply shock, permanently "removing" workers through long-term out-migration, for example, would likely have negative productivity impacts.

Our results have important implications for rural labor market analysis. The prevalence of rationing in our context suggests that there are periods when workers are not on their labor supply curve, and subsequently, wages do not play an allocative role. Therefore, in these settings, prices are uninformative (De Janvry et al., 1991) - the wage does not reflect the marginal product of labor. Moreover, analyses that aggregate labor market data to an annual horizon, averaging across lean and peak periods, will likely produce misleading estimates. This underscores the need to incorporate seasonality into labor market analysis.

As discussed above, these findings also have implications for the design of labor market policies. We provide suggestive evidence that private sector crowd-out from workfare programs is mediated by underlying labor market conditions. Our results also have implications for designing incentives for temporary migration (Bryan et al., 2014; Akram et al., 2018). However, we also acknowledge that some policy decisions require a better understanding of the specific microfoundations that give rise to labor rationing. That we find so much excess labor supply should be an impetus for more research into understanding its causes. 
Finally, our lean season results highlight how high rates of self-employment in our context make it difficult to diagnose rationing. We show that in lean seasons, so-called "disguised" unemployment (Singh et al., 1986) explains $23 \%$ of the labor workers supply to household enterprises in lean months, with this number rising to $75 \%$ for smallholder farms. This also sheds light on the nature of many small businesses in developing countries. If at least a quarter of self-employment among workers is quickly abandoned in favor of wage work, then perhaps it is not surprising that the average developing country business shows low growth and low returns to blanket interventions such as credit or skills training (Banerjee et al., 2015; McKenzie and Woodruff, 2014). This view is supported by De Mel et al. (2010), Schoar (2010) and Adhvaryu et al. (2019), who relate low-productivity entrepreneurship by workers to poor labor market prospects. This creates a rationale for targeting interventions like subsidized capital drops or skills training on "true," rather than "forced" entrepreneurs (e.g., Banerjee et al., 2019; Hussam et al., 2020).

\section{REFERENCES}

Adhvaryu, A., N. Kala, And A. Nyshadham (2019): "Booms, Busts, and Household Enterprise: Evidence from Coffee Farmers in Tanzania," The World Bank Economic Review.

Akerlof, G. A. And J. L. Yellen (1990): "The Fair Wage-Effort Hypothesis and Unemployment," The Quarterly Journal of Economics, 105, 255-283.

Akram, A. A., S. Chowdhury, and A. M. Mobarak (2018): "Effects of Emigration on Rural Labor Markets," NBER Working Paper 23929.

Anderson, S., P. Francois, And A. Kotwal (2015): "Clientelism in Indian villages," American Economic Review, 105, 1780-1816.

Arthi, V., K. Beegle, J. De Weerdt, and A. Palacios-López (2018): "Not your average job: Measuring farm labor in Tanzania," Journal of Development Economics, 130, $160-172$.

Azariadis, C. (1975): "Implicit Contracts and Underemployment Equilibria," Journal of Political Economy, 83, 1183-1202.

Banerjee, A., E. Breza, E. Duflo, and C. Kinnan (2019): "Can Microfinance Unlock a Poverty Trap for Some Entrepreneurs?" NBER Working Paper 26346.

Banerjee, A., D. Karlan, AND J. Zinman (2015): "Six randomized evaluations of microcredit: Introduction and further steps," American Economic Journal: Applied Economics, 7, 1-21.

Banerjee, A. V. And E. Duflo (2007): "The economic lives of the poor," Journal of economic perspectives, 21, 141-168. 
Bardhan, P. K. (1973): "Size, productivity, and returns to scale: An analysis of farm-level data in Indian agriculture," Journal of Political Economy, 81, 1370-1386.

(1983): "Labor-tying in a poor agrarian economy: A theoretical and empirical analysis," The Quarterly Journal of Economics, 98, 501-514.

BARRETt, C. B. (1996): "On price risk and the inverse farm size-productivity relationship," Journal of Development Economics, 51, 193-215.

Beaman, L. And J. Magruder (2012): "Who gets the job referral? Evidence from a social networks experiment," American Economic Review, 102, 3574-93.

Beegle, K. And L. Christiaensen (2019): Accelerating poverty reduction in Africa, The World Bank.

Beegle, K., E. Galasso, And J. Goldberg (2017): "Direct and Indirect Effects of Malawi's Public Works Program on Food Security," Journal of Development Economics, $1-23$.

Behrman, J. R. (1999): "Labor markets in developing countries," Handbook of labor economics, 3, 2859-2939.

Benjamin, D. (1992): "Household Composition, Labor Markets, and Labor Demand: Testing for Separation in Agricultural Household Models," Econometrica, 287-322.

Bertrand, M., B. Crépon, A. Marguerie, And P. Premand (2017): "Contemporaneous and post-program impacts of a public works program: evidence from Côte d'Ivoire," Working Paper.

Blattman, C. And S. Dercon (2018): "The impacts of industrial and entrepreneurial work on income and health: Experimental evidence from Ethiopia," American Economic Journal: Applied Economics, 10, 1-38.

Bound, J., C. Brown, And N. Mathiowetz (2001): "Measurement error in survey data," in Handbook of econometrics, Elsevier, vol. 5, 3705-3843.

Breza, E., S. Kaur, and N. Krishnaswamy (2019): "Scabs: The Social Suppression of Labor Supply," NBER Working Paper 25880.

Breza, E., S. Kaur, And Y. Shamdasani (2018): "The Morale Effects of Pay Inequality," The Quarterly Journal of Economics, 133, 611-663.

Breza, E. And C. Kinnan (2018): "Measuring the Equilibrium Impacts of Credit: Evidence from the Indian Microfinance Crisis," NBER Working Paper 24329.

Bryan, G., S. Chowdhury, and A. M. Mobarak (2014): "Underinvestment in a Profitable Technology: The Case of Seasonal Migration in Bangladesh," Econometrica, 82, 1671-1748.

CARD, D. (2011): "Origins of the unemployment rate: The lasting legacy of measurement without theory," The American Economic Review, 101, 552-557. 
Crépon, B., E. Duflo, M. Gurgand, R. Rathelot, and P. Zamora (2013): "Do Labor Market Policies have Displacement Effects? Evidence from a Clustered Randomized Experiment," The Quarterly Journal of Economics, 128, 531-580.

DAsGupta, P. AND D. RAY (1986): "Inequality as a determinant of malnutrition and unemployment: Theory," The Economic Journal, 96, 1011-1034.

De Janvry, A., M. FAfchamps, And E. SAdoulet (1991): "Peasant household behaviour with missing markets: Some paradoxes explained," The Economic Journal, 101, 1400-1417.

De Mel, S., D. MCKenzie, And C. Woodruff (2010): "Who are the microenterprise owners? Evidence from Sri Lanka on Tokman versus De Soto," in International differences in entrepreneurship, University of Chicago Press, 63-87.

Dillon, B., P. Brummund, and G. Mwabu (2019): "Asymmetric non-separation and rural labor markets," Journal of Development Economics, 139, 78-96.

Donaldson, D. And D. Keniston (2016): "Dynamics of a Malthusian Economy: India in the Aftermath of the 1918 Influenza," Working Paper.

Dreze, J., L. Leruth, And A. MukherJee (1986): "Rural Labour Markets in India: Theories and Evidence," in 8th World Congress of the International Economic Association, New Delhi, December.

Dreze, J. P. And A. MukherJee (1989): "Labour contracts in rural india: Theories and evidence," in The balance between industry and agriculture in economic development, Springer, 233-265.

Egger, D., J. Haushofer, E. Miguel, P. Niehaus, and M. W. Walker (2019): "General equilibrium effects of cash transfers: experimental evidence from Kenya," NBER Working Paper 26600.

Faberman, R. J. And A. Rajan (2020): "Is the Unemployment Rate a Good Measure of People Currently Out of Work?" Chicago Fed Insights.

FAFCHAmps, M. (1993): "Sequential labor decisions under uncertainty: An estimable household model of West-African farmers," Econometrica: Journal of the Econometric Society, 1173-1197.

Fehr, E., L. Goette, And C. Zehnder (2009): "A Behavioral Account of the Labor Market: The Role of Fairness Concerns," Annual Review of Economics, 1, 355-384.

FELlner, W. (1976): Towards a Reconstruction of Macroeconomics, American Enterprise Institute.

Fink, G., B. K. JaCK, And F. MAsiye (2018): "Seasonal Liquidity, Rural Labor Markets and Agricultural Production," NBER Working Paper 24564.

Foster, A. D. And M. R. Rosenzweig (1996): "Comparative advantage, information and the allocation of workers to tasks: Evidence from an agricultural labour market," The 
Review of Economic Studies, 63, 347-374.

(2017): "Are there too many farms in the world? Labor-market transaction costs, machine capacities and optimal farm size," NBER Working Paper 23909.

Gautier, P., P. Muller, B. van der Klaauw, M. Rosholm, and M. Svarer (2018):

"Estimating equilibrium effects of job search assistance," Journal of Labor Economics, 36, 1073-1125.

GoldberG, J. (2016): "Kwacha gonna do? Experimental Evidence about labor supply in rural Malawi," American Economic Journal: Applied Economics, 8, 129-149.

Gollin, D., D. Lagakos, And M. E. Waugh (2014): "The agricultural productivity gap," The Quarterly Journal of Economics, 129, 939-993.

Gollin, D. AND C. UDRY (2019): "Heterogeneity, measurement error and misallocation: Evidence from african agriculture," NBER Working Paper 25440.

Hussam, R., N. Rigol, And B. N. Roth (2020): "Targeting High Ability Entrepreneurs Using Community Information: Mechanism Design in the Field," Working Paper.

ImBERT, C. AND J. PAPP (2015): "Labor market effects of social programs: Evidence from India's employment guarantee," American Economic Journal: Applied Economics, 7, 233-263.

(2020): "Short-term Migration, Rural Public Works, and Urban Labor Markets: Evidence from India," Journal of the European Economic Association, 18, 927-963.

JayAChandran, S. (2006): "Selling Labor Low: Wage Responses to Productivity Shocks in Developing Countries," Journal of Political Economy, 114, 538-575.

Jones, M. R., F. Kondylis, J. A. Loeser, And J. Magruder (2020): "Factor Market Failures and the Adoption of Irrigation in Rwanda," Working Paper.

Kaur, S. (2019): "Nominal Wage Rigidity in Village Labor Markets," American Economic Review, 109, 3585-3616.

Kaur, S., S. Mullainathan, S. Oh, And F. Schilbach (2019): "Does Financial Strain Lower Productivity?" Working Paper.

Keynes, J. M. (1937): "The general theory of employment," The Quarterly Journal of Economics, 209-223.

LaFave, D. and D. Thomas (2016): "Farms, families, and markets: New evidence on completeness of markets in agricultural settings," Econometrica, 84, 1917-1960.

LaFave, D. R., E. D. Peet, And D. Thomas (2020): "Farm Profits, Prices and Household Behavior," NBER Working Paper 26636.

Leibenstein, H. (1957): Economic backwardness and economic growth : Studies in the theory of economic development., New York: Wiley.

LEwis, W. A. (1954): "Economic Development With Unlimited Supplies of Labour," The Manchester School, 22, 139-191. 
Manning, A. (2013): "Monopsony in Motion: Imperfect Competition in Labor Markets," in Monopsony in Motion, Princeton University Press.

McKenzie, D. And C. Woodruff (2014): "What are we learning from business training and entrepreneurship evaluations around the developing world?" The World Bank Research Observer, 29, 48-82.

McMillan, M. S. And D. Rodrik (2011): "Globalization, structural change and productivity growth," Tech. rep., National Bureau of Economic Research.

MukherJee, A. And D. RAY (1995): "Labor tying," Journal of Development Economics, 47, 207-239.

Muralidharan, K., P. Niehaus, and S. Sukhtankar (2020): "General Equilibrium Effects of (Improving) Public Employment Programs: Experimental Evidence from India," Working Paper.

Pitt, M. And M. Rosenzweig (1986): "Agricultural prices, food consumption, and the health and productivity of Indonesian farmers," Agricultural household models: Extensions, applications and policy, 153-182.

Rosen, S. (1985): "Implicit Contracts: A Survey," Journal of Economic Literature, 23, 1144-1175.

Rosenzweig, M. R. (1988): "Labor markets in low-income countries," in Handbook of Development Economics, Elsevier, vol. 1, 713-762.

SchOAR, A. (2010): "The divide between subsistence and transformational entrepreneurship," Innovation policy and the economy, 10, 57-81.

Schultz, T. W. (1964): Transforming traditional agriculture., Yale University Press.

SEN, A. K. (1962): "An aspect of Indian agriculture," Economic Weekly, 14, 243-246.

(1967): "Surplus labour in India: A critique of Schultz's statistical test," The Economic Journal, 154-161.

Shapiro, C. And J. E. Stiglitz (1984): "Equilibrium unemployment as a worker discipline device," The American Economic Review, 433-444.

Singh, I., L. Squire, J. Strauss, et Al. (1986): Agricultural Household Models: Extensions, Applications, and Policy, Johns Hopkins University Press.

TAYlor, J. (2008): "Involuntary unemployment," The New Palgrave Dictionary of Economics, Second Edition.

UDRY, C. (1996): "Efficiency and market structure: Testing for profit maximization in African agriculture," Working Paper.

Zimmermann, L. (2020): "Why Guarantee Employment? Evidence from a Large Indian Public-Works Program," Working Paper.

Zoutman, F. T., E. Gavrilova, and A. O. Hopland (2018): "Estimating both supply and demand elasticities using variation in a single tax rate," Econometrica, 86, 763-771. 


\section{FiguRES}

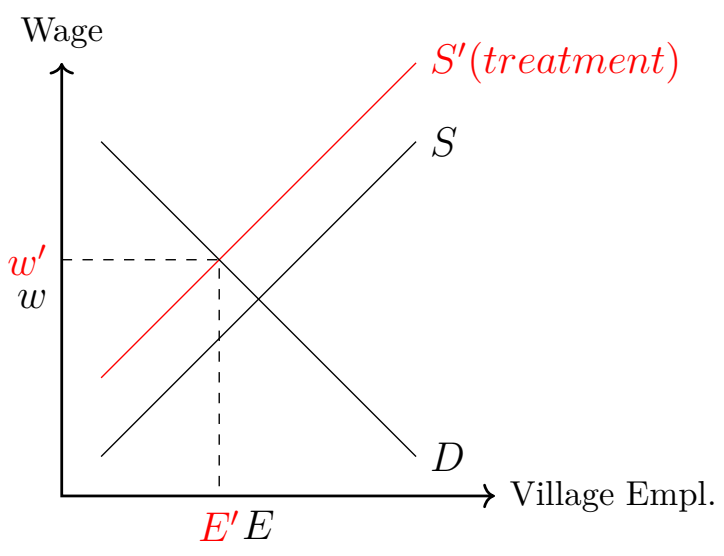

(A) $H_{0}:$ No Rationing $\left(E_{D} \geq E_{S}\right)$

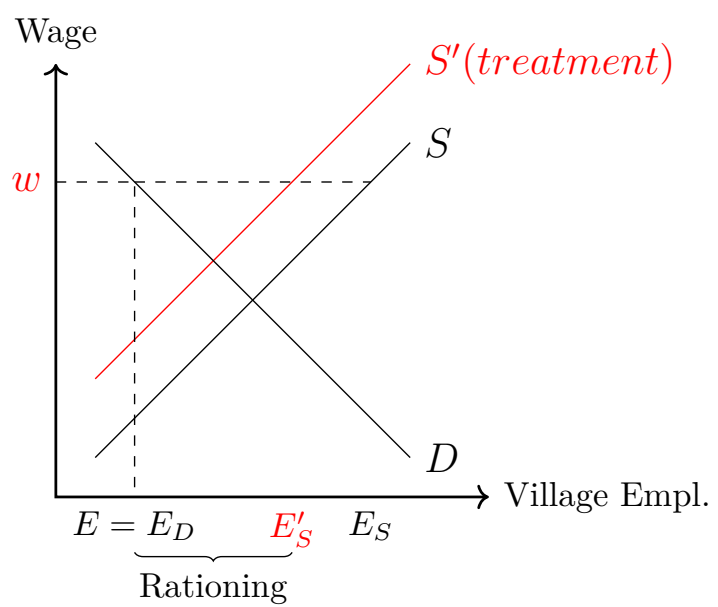

(в) $H_{1}$ : Rationing $\left(E_{D}<E_{S}\right)$

Figure 1. Effects of a Negative Labor Supply Shock

Note: Figure shows the effects of a negative supply shock on employment and wages under no rationing $\left(E_{D} \geq E_{S}\right)$ in panel $\mathrm{A}$, and under rationing $\left(E_{D}<E_{S}\right)$ in panel B.

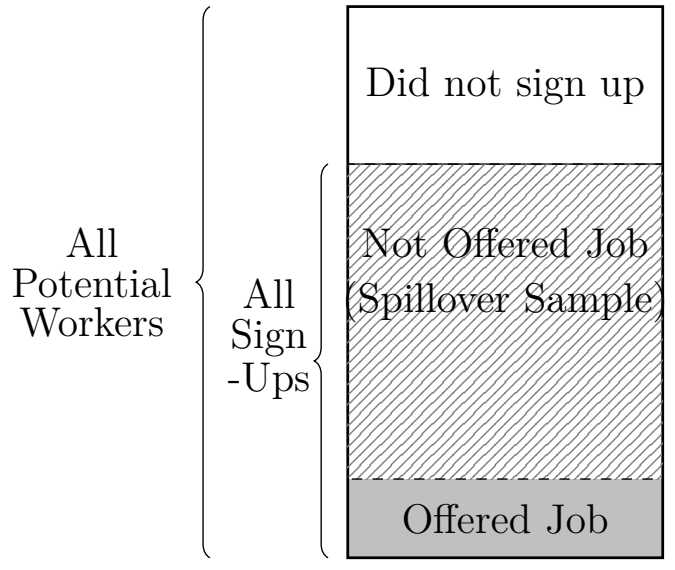

(A) No hiring shock

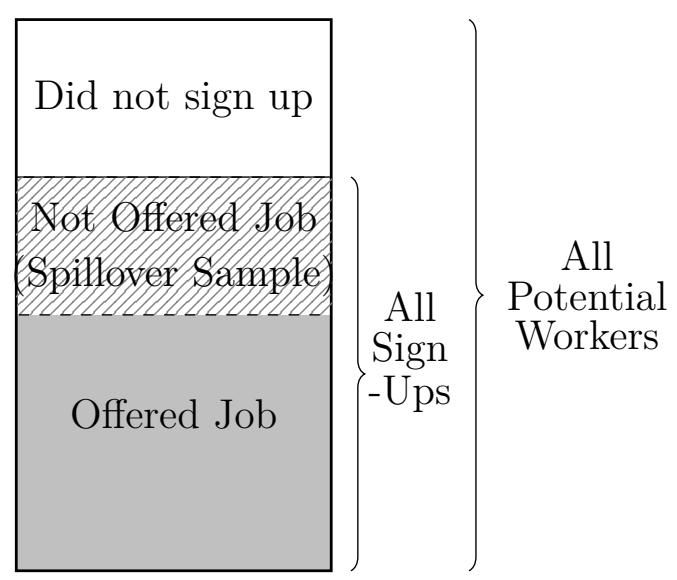

(в) Hiring shock

Figure 2. Analysis Samples

Note: Figure summarizes the analysis samples in control villages in panel A, and treatment villages in panel B. The dark grey area denotes workers who sign up and are offered employment at the external job sites (i.e. "removed" from the village). The light grey shaded area denotes workers who sign up but are not offered jobs - this constitutes the spillover sample (the main analysis sample). The sum across all three areas denotes the entire potential labor force of workers in the village. 


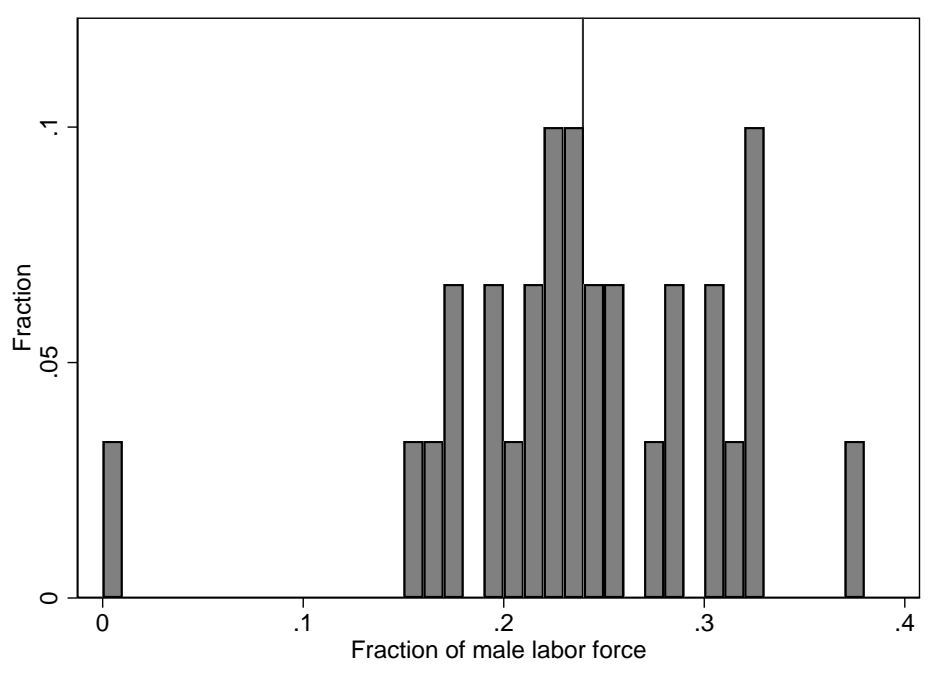

Figure 3. Size of the Experimental Hiring Shock

Note: Figure shows the size of the experimental hiring shock in treatment villages. This is measured as number of workers hired divided by the size of the male labor force in the village. The mean shock size (indicated by the dashed vertical line) is 0.24 . 


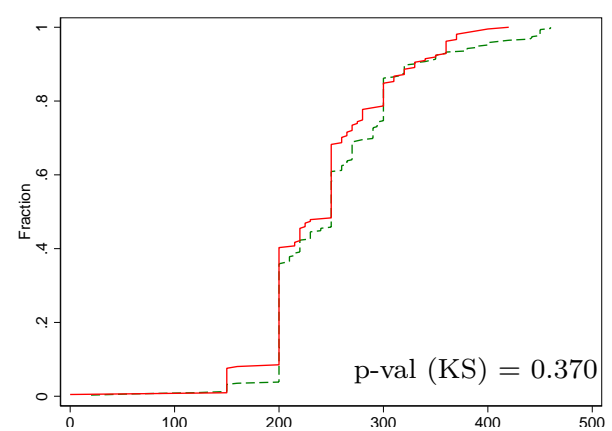

(1A) Wage - Lean

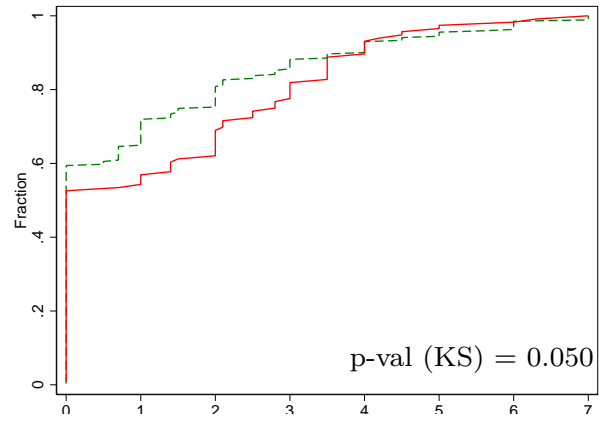

(2A) Employment Spillovers - Lean

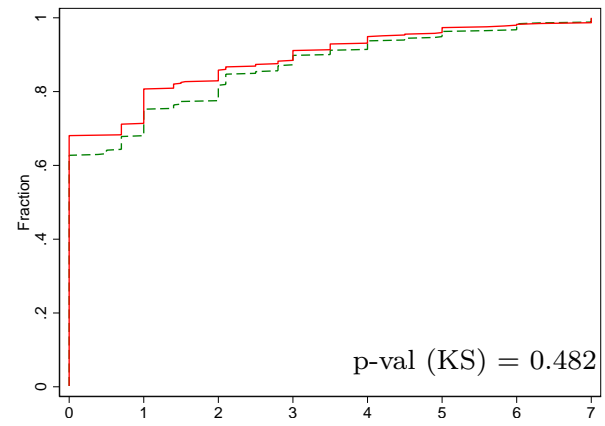

(3A) Aggregate employment - Lean

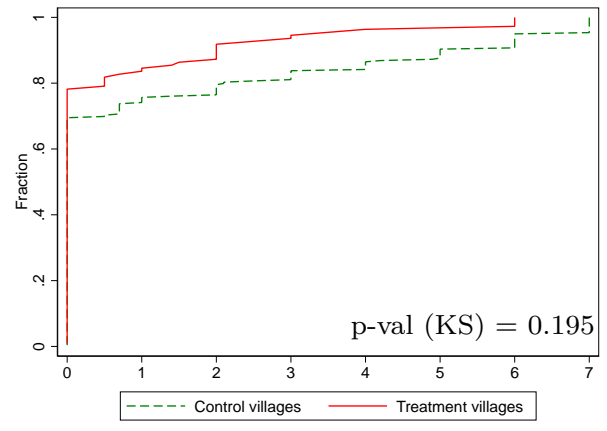

(4A) Self employment - Lean

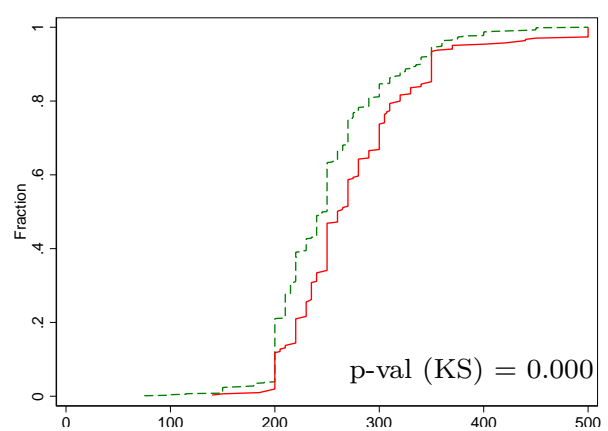

(1B) Wage - Semi-peak

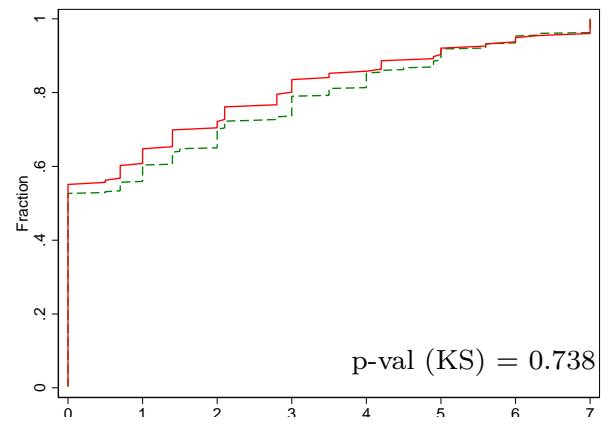

(2B) Empl. Spillovers - Semi-peak

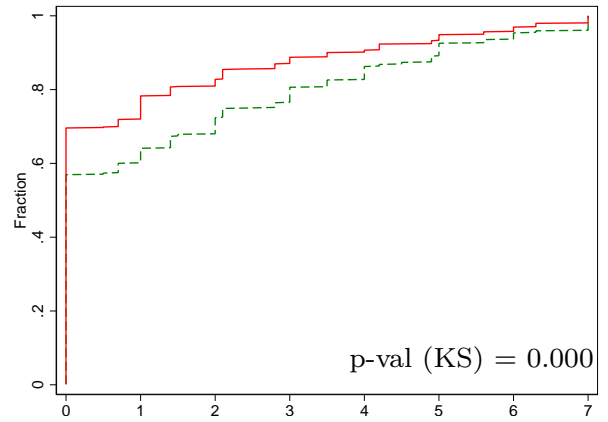

(3B) Aggregate empl. - Semi-peak

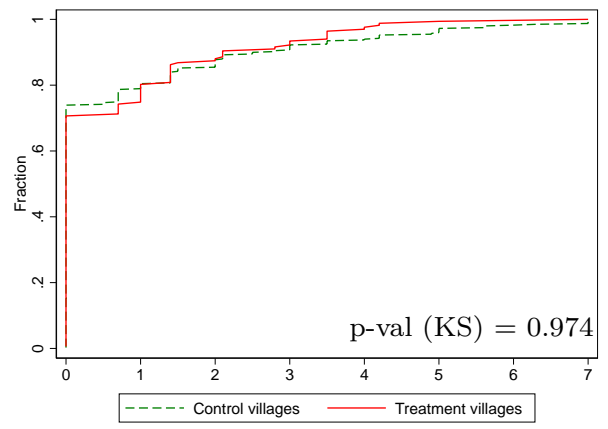

(4B) Self employment - Semi-peak

\section{FiguRE 4. Impacts of Hiring Shock}

Note: Figure compares the distribution of wages, employment spillovers, aggregate employment and self-employment for treatment and control villages, limiting the sample to lean month observations only in panel A, and semi-peak month observations only in panel B. We report the p-value for the equality of distributions from a Kolmogorov-Smirnov test in the bottom right corner of each graph. 


\section{TABLES}

TABle 1. Representativeness of Study Villages

\begin{tabular}{lccc}
\hline \hline & $(1)$ & $(2)$ & $(3)$ \\
& Study villages & All villages & P-val \\
\hline Total population & 648.5 & 773.3 & 0.286 \\
Total households & $143.075)$ & $(850.876)$ & \\
& $(80.252)$ & $(193.128)$ & \\
Total SC/ST population & 279.4 & 262.9 & 0.729 \\
Male population share & $237.695)$ & $(347.685)$ & \\
Literacy rate & 0.513 & 0.511 & 0.650 \\
& $(0.019)$ & $(0.038)$ & \\
Worker share & 0.678 & 0.661 & 0.428 \\
Male worker share & $(0.117)$ & $(0.155)$ & \\
& 0.431 & 0.402 & 0.083 \\
Main worker share & $(0.133)$ & $(0.124)$ & \\
& 0.745 & 0.769 & 0.306 \\
Agricultural labor share & $(0.176)$ & $(0.172)$ & \\
Cultivator share & 0.629 & 0.642 & 0.730 \\
& $(0.221)$ & $(0.273)$ & \\
Non-farm self-employment share & 0.164 & 0.166 & 0.940 \\
Other workers share & $(0.175)$ & $(0.191)$ & \\
& 0.228 & 0.216 & 0.637 \\
& $(0.149)$ & $(0.195)$ & \\
& 0.397 & 0.380 & 0.650 \\
\hline \hline
\end{tabular}

Notes: Observations in Col. (1) are from villages in this study, which span five districts across Odisha. We were able to match $88 \%$ of our study villages to the 2011 Census village directory $(\mathrm{N}=53)$. Observations in Col. (2) are from all other Census villages in the five study districts $(\mathrm{N}=8442)$. Col. (3) reports p-values from a comparison of means across Cols. (1) and (2). Data on village characteristics comes from the 2011 Indian Population Census. A worker is a person who participated in any economically productive activity in the last year; a main worker worked for more than 6 months in the last year. Worker share $=$ total workers/total population. The four mutually exclusive employment categories (agricultural labor, cultivator, nonfarm self-employment and other work) are based on workers' primary occupation status over the past year. Details on the construction of each variable can be found in Appendix D. 
TABle 2. Baseline Characteristics

\begin{tabular}{lcc}
\hline \hline & $(1)$ & $(2)$ \\
Panel A: Worker-Level & No hiring shock & Difference \\
\hline Landless & 0.373 & -0.019 \\
& $(0.484)$ & $(0.039)$ \\
HH Members (age 12+) & 3.965 & -0.039 \\
& $(1.543)$ & $(0.104)$ \\
Any activity & 0.358 & 0.040 \\
& $(0.363)$ & $(0.031)$ \\
Employment rate: Hired wage employment & 0.178 & 0.034 \\
& $(0.288)$ & $(0.027)$ \\
Total wage (Rs.) & 251.968 & -1.863 \\
& $(60.904)$ & $(9.040)$ \\
Public works employment & 0.005 & 0.003 \\
& $(0.058)$ & $(0.004)$ \\
Has HH business & 0.879 & -0.026 \\
& $(0.326)$ & $(0.024)$ \\
Self employment & 0.115 & -0.017 \\
& $(0.244)$ & $(0.021)$ \\
Days would like to work in labor market (in next 30 days) & 18.217 & -0.216 \\
& $(8.496)$ & $(0.406)$ \\
Panel B: Village-Level & & \\
\hline Fraction of sign-ups & & \\
Total households & 0.423 & 0.00967 \\
Total SC/ST population & $(0.104)$ & $(0.021)$ \\
Literacy rate & 145.1 & 21.67 \\
Worker share & $(92.731)$ & $(16.276)$ \\
Main worker share & 319.0 & -71.62 \\
& $(266.111)$ & $(46.122)$ \\
& 0.679 & -0.00186 \\
& $(0.126)$ & $(0.023)$ \\
& 0.408 & 0.0382 \\
& $(0.131)$ & $(0.032)$ \\
& 0.647 & -0.0282 \\
& $(0.221)$ & $(0.066)$ \\
\hline
\end{tabular}

Notes: Panel A presents baseline characteristics for the spillover sample (workers who signed up for external jobs but were not offered employment) at the worker level (N=992). Panel B presents baseline characteristics at the village level using data from the experiment $(\mathrm{N}=60)$ as well as data from the 2011 Indian Population Census $(\mathrm{N}=53 ; 88 \%$ match rate between our study villages and 2011 Census villages). A worker is a person who participated in any economically productive activity in the last year; worker share $=$ total workers/total population. A main worker is a person who worked for more than 6 months in the last year; main worker share $=$ total main workers/total workers. Details on the construction of the Census variables can be found in Appendix D. Col. (1) presents baseline means and standard deviations of characteristics in control villages. Col. (2) reports coefficients from regressing the covariate in each row on a dummy for treatment with round (strata) fixed effects and standard errors clustered at the village level. 
TABLE 3. Wage Effects

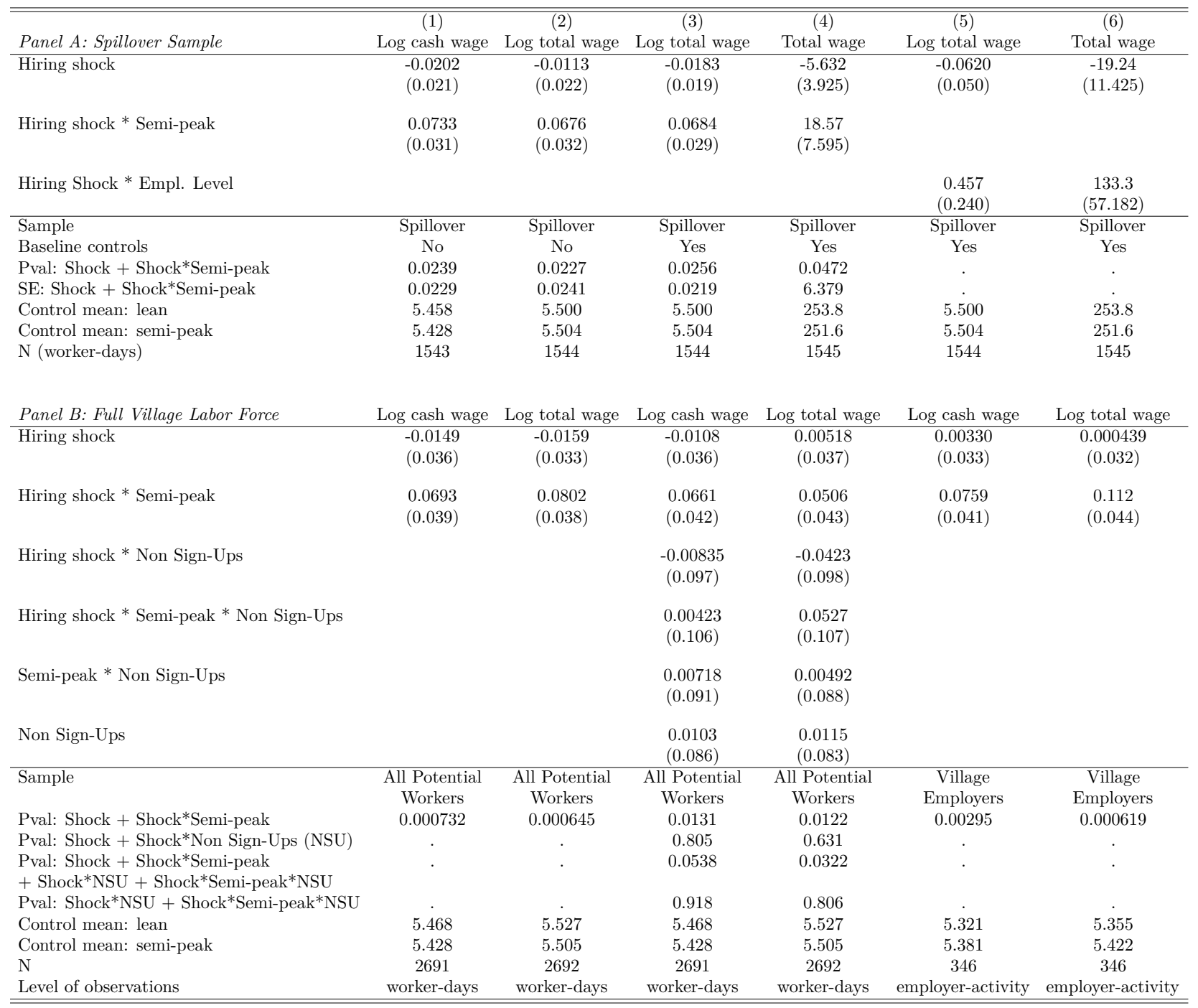

Notes: Observations in Panel A are from the spillover sample (workers who signed up for external jobs but were not offered employment). Observations in Cols. (1)-(4) of Panel B are from all potential workers in the village with appropriate weights, and observations in Cols. (5)-(6) of Panel B are from a sample of employers surveyed in the village. Total wage $=$ cash + in-kind wages. We winsorize the top one percentile of the cash and total wage distributions. In control villages, mean total wages for the spillover sample are Rs. 253.8 (lean) and Rs. 251.6 (semi-peak), and for the non sign-ups are Rs. 279.8 (lean) and Rs. 251.5 (semi-peak). Controls in Panel A and Cols. (1)-(4) of Panel B include worker-level mean employment and wage levels at baseline. Regressions include round (strata) FEs. Standard errors clustered at the village level in parentheses. 
TABLE 4. Alternate Measures of Wages \& Wage Contract

\begin{tabular}{|c|c|c|c|c|c|c|}
\hline & $\begin{array}{l}\text { (1) } \\
\text { Hourly total wage }\end{array}$ & $\begin{array}{c}(2) \\
\text { Hours per day }\end{array}$ & $\begin{array}{c}\text { (3) } \\
\text { Expected Days of Work }\end{array}$ & $\begin{array}{c}(4) \\
\text { Expect Loan }\end{array}$ & $\begin{array}{c}(5) \\
\text { Paid Immediately }\end{array}$ & $\begin{array}{c}(6) \\
\text { Paid an Advance }\end{array}$ \\
\hline Hiring shock & $\begin{array}{l}-0.504 \\
(1.070)\end{array}$ & $\begin{array}{l}0.00710 \\
(0.116)\end{array}$ & $\begin{array}{l}-0.179 \\
(4.426)\end{array}$ & $\begin{array}{r}-0.0943 \\
(0.065)\end{array}$ & $\begin{array}{l}0.0906 \\
(0.048)\end{array}$ & $\begin{array}{r}-0.0663 \\
(0.040)\end{array}$ \\
\hline Hiring shock $*$ Semi-peak & $\begin{array}{l}4.211 \\
(2.140)\end{array}$ & $\begin{array}{l}0.0998 \\
(0.224)\end{array}$ & $\begin{array}{l}-0.125 \\
(5.500)\end{array}$ & $\begin{array}{c}0.198 \\
(0.106)\end{array}$ & $\begin{array}{l}-0.112 \\
(0.096)\end{array}$ & $\begin{array}{l}0.0840 \\
(0.073)\end{array}$ \\
\hline Sample & Spillover & Spillover & Spillover & Spillover & Spillover & Spillover \\
\hline Pval: Shock + Shock*Semi-peak & 0.0505 & 0.580 & 0.927 & 0.229 & 0.802 & 0.774 \\
\hline SE: Shock + Shock*Semi-peak & 1.854 & 0.192 & 3.265 & 0.0835 & 0.0827 & 0.0608 \\
\hline Control mean: lean & 42.74 & 6.354 & 14.96 & 0.342 & 0.849 & 0.0959 \\
\hline Control mean: semi-peak & 44.04 & 5.910 & 15.04 & 0.343 & 0.806 & 0.104 \\
\hline+5 & 1470 & 1470 & 223 & 262 & 262 & 262 \\
\hline Level of observations & worker-day & worker-day & worker & worker & worker & worker \\
\hline
\end{tabular}

Notes: Observations are from the spillover sample (workers who signed up for external jobs but were not offered employment). Hourly total wage = total (cash + in-kind) wages/total hours worked that day. Hours per day = total hours worked that day. For a subset of experimental rounds, workers were asked a series of questions about all the employers they had worked for in the past 10 days — these responses are summarized in Cols. (3) to (6). Expected days of work = total number of days of work till the next harvest they expect from these employers. Expect Loan $=1\{$ expect a loan from these employers $\}$. Paid immediately $=1\{$ paid immediately for work by these employers $\}$. Paid an advance $=1\{$ paid an advance by these employers\}. Regressions include round (strata) FEs. Standard errors are clustered at the village level in parentheses. 
TABLE 5. Employment Spillovers

\begin{tabular}{lccc}
\hline \hline & $(1)$ & $(2)$ & $(3)$ \\
& Hired wage empl. & Hired wage empl. & Hired wage empl. \\
\hline Hiring shock & 0.0684 & 0.0544 & 0.138 \\
& $(0.021)$ & $(0.019)$ & $(0.045)$ \\
Hiring shock * Semi-peak & -0.0737 & -0.0735 & \\
& $(0.034)$ & $(0.030)$ & \\
& & & \\
Hiring Shock * Empl. Level & & & -0.706 \\
& & & $(0.254)$ \\
\hline Sample & Spillover & Spillover & Spillover \\
Baseline controls & No & Yes & Yes \\
Pval: Shock + Shock*Semi-peak & 0.840 & 0.427 & $\cdot$ \\
SE: Shock + Shock*Semi-peak & 0.0265 & 0.0239 &. \\
Control mean: lean & 0.145 & 0.145 & 0.145 \\
Control mean: semi-peak & 0.216 & 0.216 & 0.216 \\
N (worker-days) & 8906 & 8906 & 8906 \\
\hline \hline
\end{tabular}

Notes: Observations are from the spillover sample (workers who signed up for external jobs but were not offered employment). Hired wage employment $=1$ \{worker hired that day and paid a wage \}. Controls comprised of worker-level mean employment and wage levels at baseline. Regressions include round (strata) FEs. Standard errors are clustered at the village level in parentheses. 
TABle 6. Aggregate Employment Effects and Crowd-Out

\begin{tabular}{|c|c|c|c|c|c|}
\hline & (1) & $(2)$ & $(3)$ & (4) & $(5)$ \\
\hline & Hired wage empl. & Hired wage empl. & Hired wage empl. & Hiring shock empl. & Hired wage empl. \\
\hline Hiring shock & 0.0108 & 0.0693 & -0.00604 & 0.188 & \\
\hline & $(0.022)$ & $(0.048)$ & $(0.021)$ & $(0.012)$ & \\
\hline Hiring shock $*$ Semi-peak & -0.0534 & & -0.0450 & 0.00611 & \\
\hline & $(0.026)$ & & $(0.024)$ & $(0.019)$ & \\
\hline Hiring Shock * Empl. Level & & -0.506 & & & \\
\hline & & $(0.234)$ & & & \\
\hline Hiring shock empl. & & & & & -0.0313 \\
\hline & & & & & $(0.106)$ \\
\hline Hiring shock empl. * Semi-peak & & & & & -0.232 \\
\hline & & & & & $(0.120)$ \\
\hline Sample & All Potential & All Potential & All Potential & All Potential & All Potential \\
\hline sample2 & Workers & Workers & Workers & Workers & Workers \\
\hline Baseline controls & Yes & Yes & Yes & Yes & Yes \\
\hline Pval: Shock + Shock*Semi-peak & 0.00395 & . & 0.00150 & $3.32 \mathrm{e}-20$ & 0.000167 \\
\hline SE: Shock + Shock*Semi-peak & 0.0142 & . & 0.0153 & 0.0140 & 0.0700 \\
\hline Control mean: lean & 0.135 & 0.135 & 0.169 & 0.0357 & 0.169 \\
\hline Control mean: semi-peak & 0.195 & 0.195 & 0.205 & 0.0233 & 0.205 \\
\hline Specification & & & $\mathrm{RF}$ & FS & IV \\
\hline $\mathrm{N}$ & 21085 & 21085 & 738 & 738 & 738 \\
\hline Level of observations & worker-days & worker-days & village-days & village-days & village-days \\
\hline
\end{tabular}

Notes: Observations are from all potential workers in the village. Each observation in Cols. (1) and (2) is at the worker-day level, with appropriate weights. Controls in Cols. (1) and (2) comprised of worker-level and village-level mean employment and wage levels at baseline. Each observation in Cols. (3) to (5) is an average at the village-day level. Controls in Cols. (3) to (5) comprised of mean employment and wages at the village-day level at baseline, averaging both across the whole village sample and the subset of individuals with an employment observation on that day. Regressions in Cols. (3) to (5) use analytical weights to weigh by the number of endline observations present in the village on each day. Regressions include round (strata) FE. Standard errors are clustered at the village level in parentheses. 
TABLE 7. Impacts 2 Weeks After End of Hiring Shock

\begin{tabular}{|c|c|c|c|c|}
\hline & $\begin{array}{c}(1) \\
\text { Log total wage }\end{array}$ & $\begin{array}{c}(2) \\
\text { Log total wage }\end{array}$ & $\begin{array}{c}(3) \\
\text { Hired wage employment }\end{array}$ & $\begin{array}{c}(4) \\
\text { Self employment }\end{array}$ \\
\hline Hiring shock & $\begin{array}{r}-0.0241 \\
(0.038)\end{array}$ & $\begin{array}{c}0.00410 \\
(0.035)\end{array}$ & $\begin{array}{c}-0.00846 \\
(0.027)\end{array}$ & $\begin{array}{c}-0.0177 \\
(0.015)\end{array}$ \\
\hline Hiring shock $*$ Semi-peak & $\begin{array}{c}0.0673 \\
(0.044)\end{array}$ & $\begin{array}{c}0.0362 \\
(0.042)\end{array}$ & $\begin{array}{c}-0.0378 \\
(0.034)\end{array}$ & $\begin{array}{c}-0.0193 \\
(0.024)\end{array}$ \\
\hline Sample & Spillover & Spillover & Spillover & Spillover \\
\hline Baseline controls & No & Yes & Yes & Yes \\
\hline Pval: Shock + Shock*Semi-peak & 0.0537 & 0.109 & 0.0255 & 0.0531 \\
\hline SE: Shock + Shock*Semi-peak & 0.0219 & 0.0247 & 0.0201 & 0.0187 \\
\hline Control mean: lean & 5.529 & 5.529 & 0.177 & 0.162 \\
\hline Control mean: semi-peak & 5.532 & 5.532 & 0.211 & 0.134 \\
\hline N (worker-days) & 1328 & 1328 & 7623 & 7623 \\
\hline
\end{tabular}

Notes: Observations are from the spillover sample (workers who signed up for external jobs but were not offered employment). Total wage $=$ cash + in-kind wages. Hired wage employment $=1$ \{worker hired that day and paid a wage $\}$. Self employment $=1$ \{worker self-employed that day $\}$. Controls in Cols. (2)-(3) comprised of worker-level mean employment and wage levels at baseline. Controls in Col. (4) include worker-level indicators for any self-employment activities at baseline. Regressions include round (strata) FE. Standard errors clustered at the village level in parentheses. 
TABLE 8. Self-Employment

\begin{tabular}{|c|c|c|c|c|c|c|c|}
\hline & $\begin{array}{c}(1) \\
\text { Self empl. }\end{array}$ & $\begin{array}{ll} & (2) \\
\text { Self: } & \text { non-agri } \\
\end{array}$ & $\begin{array}{c}(3) \\
\text { Self: agri }\end{array}$ & $\begin{array}{c}\text { (4) } \\
\text { Self: agri }\end{array}$ & $\begin{array}{c}(5) \\
\text { Total farm labor }\end{array}$ & $\begin{array}{c}(6) \\
\text { HH self empl. }\end{array}$ & $\begin{array}{c}(7) \\
\text { HH self empl. }\end{array}$ \\
\hline Hiring shock & $\begin{array}{l}-0.0336 \\
(0.019)\end{array}$ & $\begin{array}{l}-0.0333 \\
(0.011)\end{array}$ & $\begin{array}{l}-0.0300 \\
(0.023)\end{array}$ & $\begin{array}{l}-0.0716 \\
(0.028)\end{array}$ & $\begin{array}{l}-2.066 \\
(0.801)\end{array}$ & $\begin{array}{l}-1.117 \\
(0.431)\end{array}$ & $\begin{array}{l}-0.569 \\
(0.324)\end{array}$ \\
\hline $\begin{array}{l}\text { Hiring shock } \\
\text { * Above Median Land Per Capita }\end{array}$ & & & & $\begin{array}{l}0.0690 \\
(0.049)\end{array}$ & $\begin{array}{l}1.213 \\
(1.219)\end{array}$ & & \\
\hline Hiring shock $*$ Semi-peak & $\begin{array}{c}0.00289 \\
(0.027)\end{array}$ & $\begin{array}{c}-0.00337 \\
(0.019)\end{array}$ & $\begin{array}{l}0.0207 \\
(0.027)\end{array}$ & $\begin{array}{c}0.118 \\
(0.036)\end{array}$ & $\begin{array}{c}2.333 \\
(0.868)\end{array}$ & $\begin{array}{l}1.019 \\
(0.531)\end{array}$ & $\begin{array}{c}0.692 \\
(0.354)\end{array}$ \\
\hline $\begin{array}{l}\text { Hiring shock* Semi-peak } \\
* \text { Above Median Land Per Capita }\end{array}$ & & & & $\begin{array}{l}-0.181 \\
(0.060)\end{array}$ & $\begin{array}{l}-2.587 \\
(1.301)\end{array}$ & & \\
\hline Sample & Spillover & Spillover & Spillover & Spillover & Spillover & Spillover & $\begin{array}{l}\text { All Potential } \\
\text { Workers }\end{array}$ \\
\hline Baseline controls & Yes & Yes & Yes & Yes & Yes & Yes & Yes \\
\hline Pval: Shock + Shock*Semi-peak & 0.118 & 0.0213 & 0.548 & 0.0548 & 0.476 & 0.763 & 0.524 \\
\hline SE: Shock + Shock*Semi-peak & 0.0193 & 0.0151 & 0.0154 & 0.0236 & 0.372 & 0.323 & 0.191 \\
\hline Control mean: lean & 0.139 & 0.0443 & 0.149 & 0.149 & 4.802 & 3.432 & 1.499 \\
\hline Control mean: semi-peak & 0.109 & 0.0441 & 0.0823 & 0.0823 & 1.607 & 1.627 & 1.318 \\
\hline $\mathrm{N}$ & 8381 & 5007 & 7513 & 7513 & 813 & 914 & 2180 \\
\hline Level of observations & worker-days & worker-days & worker-days & worker-days & households & households & households \\
\hline
\end{tabular}

Notes: Observations are from the spillover sample (workers who signed up for external jobs but were not offered employment) in Cols. (1)-(6), and from all potential workers in the village with appropriate weights in Col. (7). Self employment $=1$ \{worker self-employed that day\}. Self employment: non-agri $=1$ \{worker self-employed in non-agriculture that day\}. Self employment: agri $=1$ \{worker self-employed in agriculture that day\}. Total farm labor = total number of worker-days (own family labor + hired labor) used on the farm over the past week. Household self employment $=$ total number of worker-days in self-employment across all household members in the past week. We restrict the sample to experimental rounds with non-zero self-employment in control villages at endline in Cols. (1), (6) and (7), non-zero non-agricultural selfemployment in control villages at endline in Col. (2), and non-zero agricultural self-employment in control villages at endline in Cols. (3)-(5). Controls include worker-level indicators for any self-employment activities at baseline. Regressions include round (strata) FE. Standard errors clustered at the village level in parentheses. 
TABLE 9. Measuring Involuntary Unemployment

\begin{tabular}{|c|c|c|c|c|c|c|}
\hline & $\begin{array}{c}(1) \\
\text { Any } \\
\text { work }\end{array}$ & $\begin{array}{c}(2) \\
\text { Any } \\
\text { work }\end{array}$ & $\begin{array}{c}(3) \\
\text { Invol unempl } \\
\text { (traditional) }\end{array}$ & $\begin{array}{c}(4) \\
\text { Invol unempl } \\
\text { (traditional) }\end{array}$ & $\begin{array}{c}(5) \\
\text { Invol unempl } \\
\text { (alternate) }\end{array}$ & $\begin{array}{c}(6) \\
\text { Invol unempl } \\
\text { alternate) }\end{array}$ \\
\hline Hiring shock & $\begin{array}{l}0.0222 \\
(0.028)\end{array}$ & $\begin{array}{l}0.0153 \\
(0.023)\end{array}$ & $\begin{array}{c}-0.0385 \\
(0.028)\end{array}$ & $\begin{array}{c}-0.0322 \\
(0.027)\end{array}$ & $\begin{array}{c}-0.0699 \\
(0.026)\end{array}$ & $\begin{array}{c}-0.0611 \\
(0.026)\end{array}$ \\
\hline Hiring shock $*$ Semi-peak & $\begin{array}{c}-0.0264 \\
(0.035)\end{array}$ & $\begin{array}{c}-0.0282 \\
(0.029)\end{array}$ & $\begin{array}{c}0.0296 \\
(0.039)\end{array}$ & $\begin{array}{c}0.0300 \\
(0.038)\end{array}$ & $\begin{array}{c}0.0638 \\
(0.039)\end{array}$ & $\begin{array}{c}0.0647 \\
(0.038)\end{array}$ \\
\hline Sample & Spillover & Spillover & Spillover & Spillover & Spillover & Spillover \\
\hline Baseline controls & No & Yes & No & Yes & No & Yes \\
\hline Pval: Shock + Shock*Semi-peak & 0.842 & 0.477 & 0.741 & 0.932 & 0.837 & 0.900 \\
\hline SE: Shock + Shock*Semi-peak & 0.0207 & 0.0181 & 0.0267 & 0.0260 & 0.0297 & 0.0285 \\
\hline Control mean: lean & 0.341 & 0.341 & 0.482 & 0.482 & 0.580 & 0.580 \\
\hline Control mean: semi-peak & 0.398 & 0.398 & 0.395 & 0.395 & 0.540 & 0.540 \\
\hline N (worker-days) & 8906 & 8906 & 8906 & 8906 & 8906 & 8906 \\
\hline
\end{tabular}

Notes: Observations are from the spillover sample (workers who signed up for external jobs but were not offered employment). Any work $=1\{$ worker reports any work that day $\}$. Involuntary unemployment (traditional) $=1\{$ worker reports "would have liked to work but was unable to find any" as his activity status for that day . Involuntary unemployment (alternate) $=1\{$ worker states that they would have accepted a job at the prevailing wage over whatever else they had been doing that day\}. Controls include worker-level mean employment and wage levels at baseline. Regressions include round (strata) FE. Standard errors clustered at the village level in parentheses. Test comparing the coefficients in Cols. 3 vs. $5: \mathrm{p}$-val $=0.0674$. Test comparing the coefficients in Cols. 4 vs. $6: \mathrm{p}$-val $=0.1147$. 


\section{FOR ONLINE PUBLICATION}

\section{Appendix A. Appendix Figures}

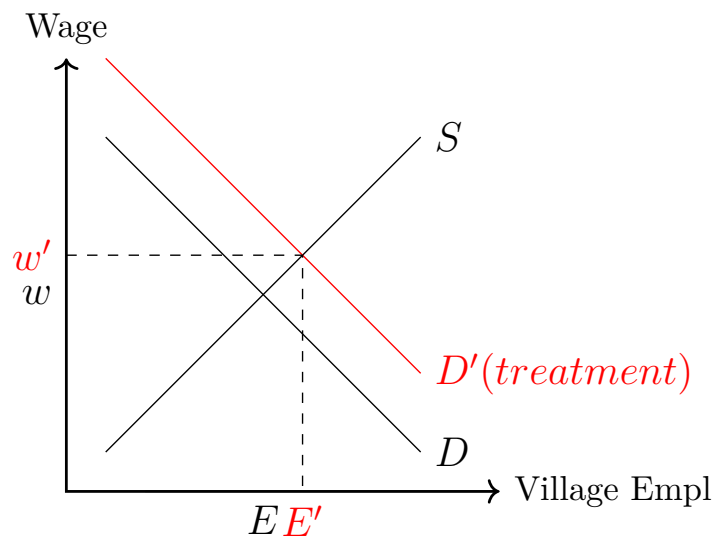

(A) $H_{0}:$ No Rationing $\left(E_{D} \geq E_{S}\right)$

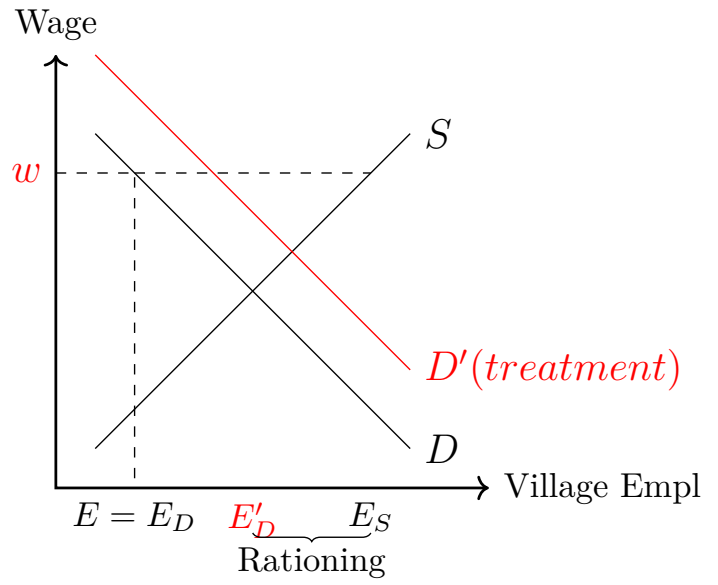

(в) $H_{1}:$ Rationing $\left(E_{D}<E_{S}\right)$

Figure A.1. Effects of a Negative Labor Demand Shock

Note: Figure shows the effects of a negative demand shock on employment and wages under no rationing $\left(E_{D} \geq E_{S}\right)$ in panel $\mathrm{A}$, and under rationing $\left(E_{D}<E_{S}\right)$ in panel B. 


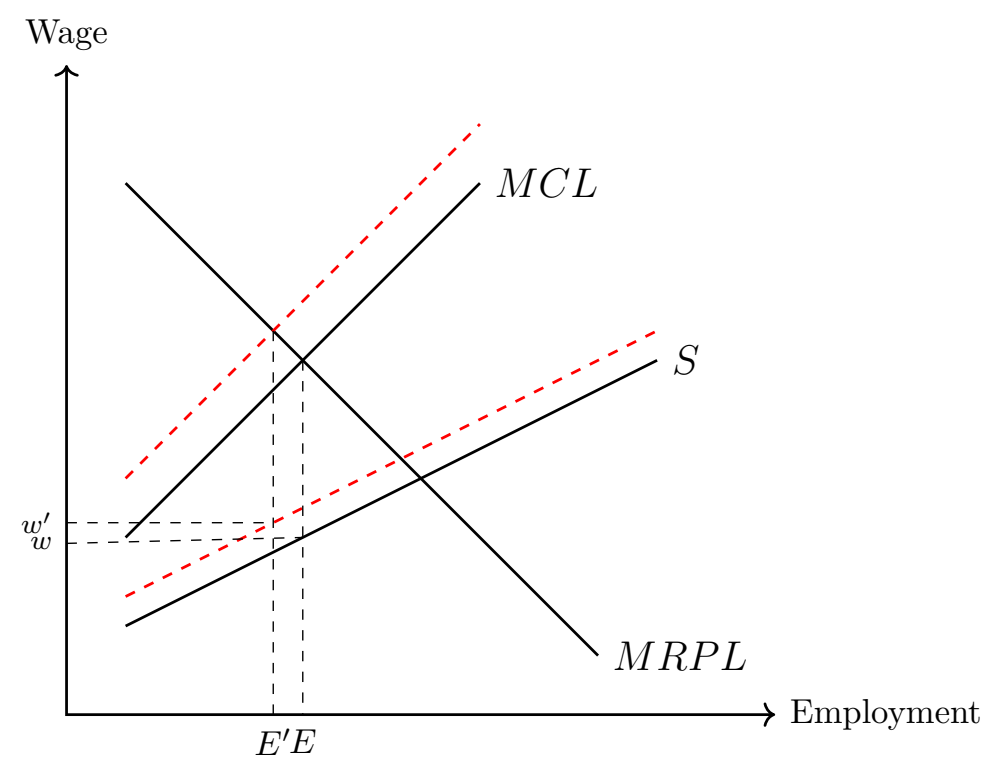

Figure A.2. Effects of a Negative Labor Supply Shock Under Monopsony

Note: Figure shows the effects of a negative supply shock on employment and wages under monopsony. A parallel shift in labor supply leads wages to rise and employment to fall, the same qualitative predictions as in the benchmark, market clearing model. Because the marginal cost of labor curve is steeper than the labor supply curve, the wage increases by less and employment decreases by more under monopsony, relative to market clearing.

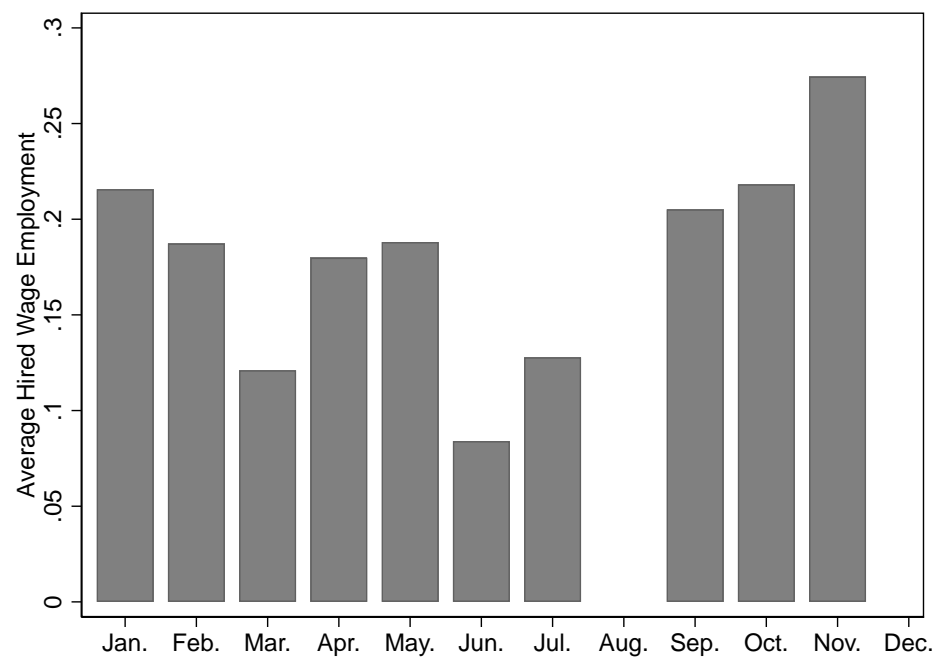

Figure A.3. Average Hired Wage Employment Rate by Month

Note: Figure plots average wage employment rates in control villages by calendar month. The median employment rate is 0.19 . 


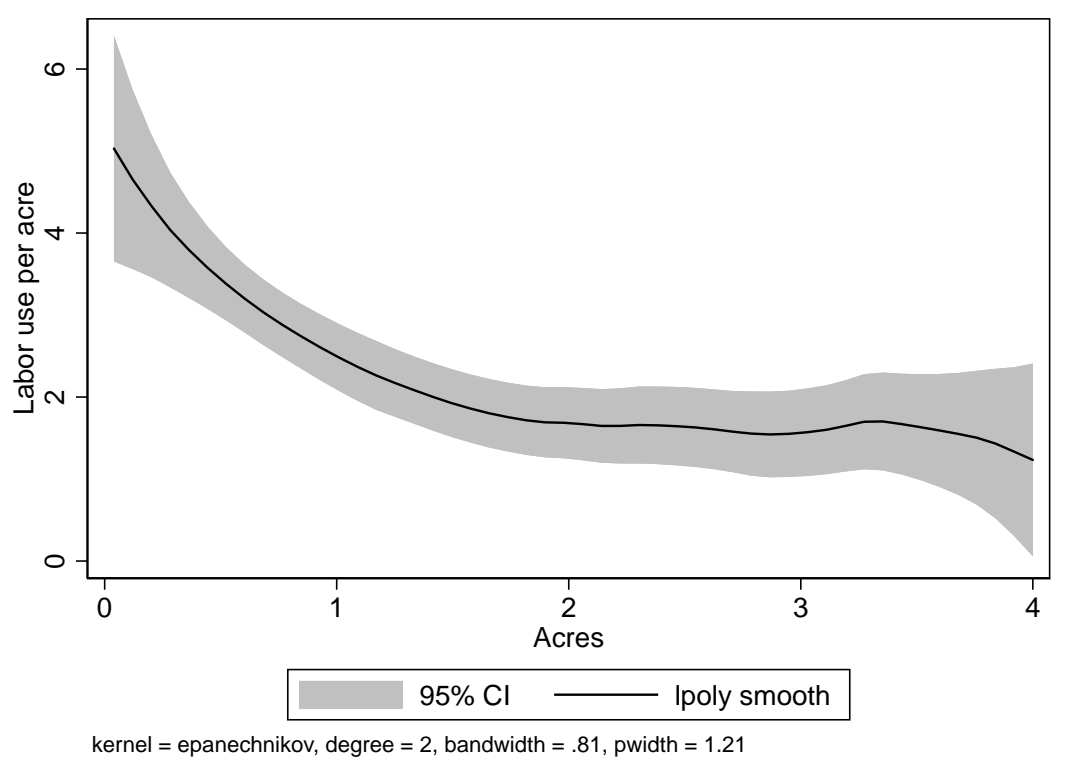

Figure A.4. Inverse Farm-Size Relationship

Note: Figure plots intensity of labor use against farm size. The y-axis measures total labor inputs per acre on the farm in the past week (own family labor + hired labor).

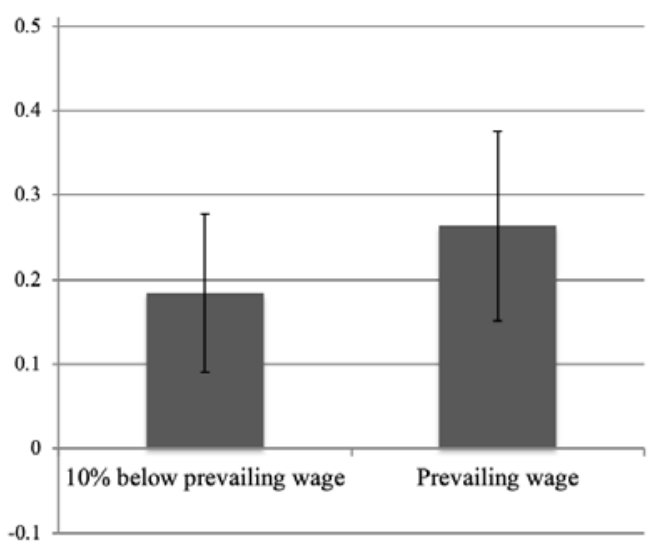

Figure A.5. Job take-up

Note: Figure illustrates take up of a job offer made in private at different wage rates among casual workers in villages similar to our study sample, in the same districts of Odisha, India. This data comes from a labor supply estimation exercise conducted by Breza et al. (2019). 


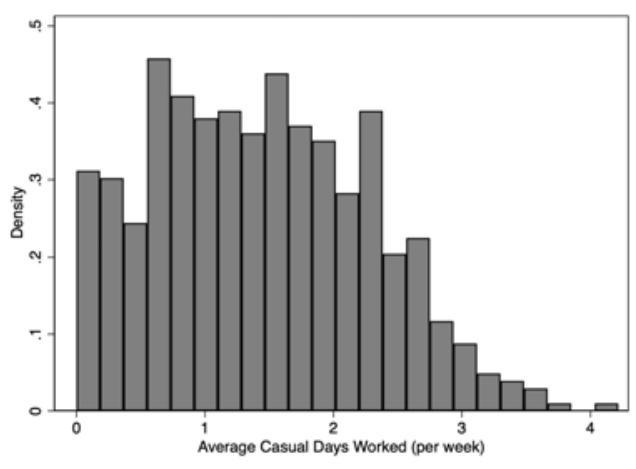

(A) Average Casual Employment Across Districts

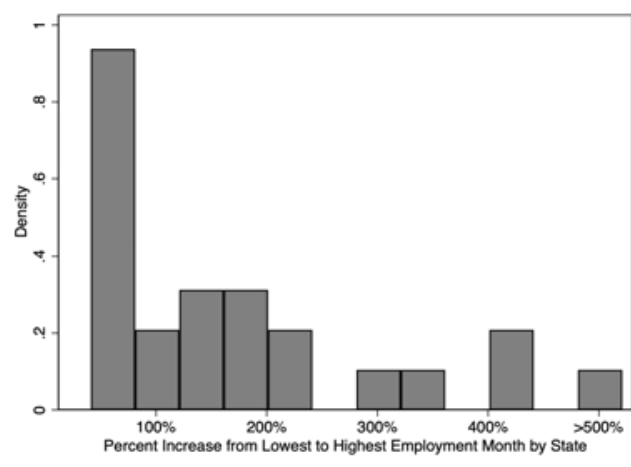

(B) Percent Increase in Casual Employment from Lowest to Highest Month Across States

Figure A.6. India-wide Variation in Employment by District and Month

Note: Data is from from the rural sample of Round 61 of the National Sample Survey, pre-NREGA roll-out. Panel A shows the distribution of weekly average casual employment across districts in India. Panel B shows the distribution of the percent difference between the months with the highest and lowest rate of casual employment across states. For both panels, the sample is restricted to individuals whose primary or secondary occupation is casual labor or agricultural self employment.

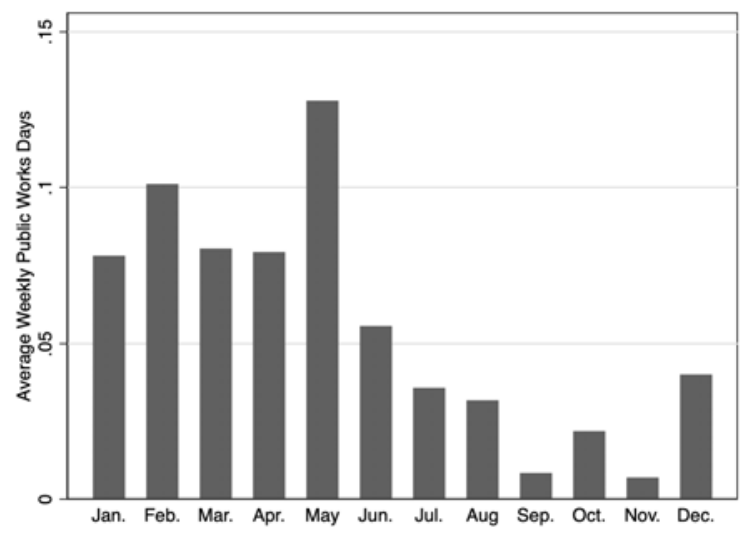

Figure A.7. Average Weekly Days in Public Works by Month

Note: Figure plots weekly average public works employment in each month using data from Round 64 of the National Sample Survey (post-NREGA rollout). The sample is restricted to districts that received the NREGA program by Round 64 . 
Appendix B. Appendix Tables

Table B.1. Survey Completion in Spillover Sample

\begin{tabular}{lcc}
\hline \hline & $(1)$ & $(2)$ \\
& Baseline Survey Completion & Endline Survey Completion \\
\hline Hiring shock & 0.0160 & 0.0125 \\
& $(0.019)$ & $(0.014)$ \\
\hline Sample & Spillover & Spillover \\
Dep Var Mean & 0.934 & 0.896 \\
N (workers) & 1094 & 1108 \\
\hline \hline
\end{tabular}

Notes: Observations are from the spillover sample (workers who signed up for external jobs but were not offered employment). The dependent variable is a binary indicator for whether the survey respondent completed the survey. Col. (1) examines baseline survey responses and Col. (2) examines endline survey responses. Regressions include round (strata) FEs. The regression in Col. (2) includes a control for baseline survey completion. Standard errors are clustered at the village level in parentheses. 
TABle B.2. Sample Sizes \& Survey Completion Rates

\begin{tabular}{|c|c|c|c|c|c|}
\hline & \multicolumn{2}{|l|}{ Lean } & \multicolumn{2}{|c|}{ Semi-Peak } & Hiring shock \\
\hline & $(1)$ & $(2)$ & $(3)$ & $(4)$ & $(5)$ \\
\hline & No hiring shock & Difference & No hiring shock & Difference & Lean vs Semi-Peak \\
\hline \multirow[t]{2}{*}{ Total Sign-Ups } & 28.15 & 1.538 & 33.53 & 3.353 & 1.814 \\
\hline & $(13.53)$ & $(2.675)$ & $(12.08)$ & $(3.923)$ & $(4.749)$ \\
\hline \multirow[t]{2}{*}{ EL Survey Completion: Spillover } & 0.877 & 0.0260 & 0.901 & 0.00409 & -0.0219 \\
\hline & $(0.329)$ & $(0.0254)$ & $(0.298)$ & $(0.0157)$ & $(0.0297)$ \\
\hline \multirow{2}{*}{ Total Non Sign-Ups } & 15 & -1.500 & 15.43 & -0.0714 & 1.429 \\
\hline & $(4.721)$ & $(0.512)$ & $(7.703)$ & $(0.898)$ & $(1.034)$ \\
\hline \multirow[t]{2}{*}{ EL Survey Completion: Non Sign-Ups } & 0.770 & 0.0336 & 0.898 & -0.0304 & -0.0640 \\
\hline & $(0.0877)$ & $(0.0548)$ & $(0.102)$ & $(0.0415)$ & $(0.0687)$ \\
\hline \multirow[t]{2}{*}{ Share of Non Sign-Ups Surveyed } & 0.177 & -0.0219 & 0.169 & -0.0133 & 0.00862 \\
\hline & $(0.0451)$ & $(0.0116)$ & $(0.0418)$ & $(0.0133)$ & $(0.0177)$ \\
\hline
\end{tabular}

Notes: Cols. (1) and (3) present means and standard deviations of village-level outcomes in control villages in lean and semi-peak months respectively. Col. (2) reports differences in outcomes by treatment status in lean months, Col. (4) reports differences in outcomes by treatment status in semi-peak months, and Col. (5) reports differences in outcomes across lean and semi-peak months, for treated villages. These differences are coefficients from a regression of the covariates in each row on dummies for treatment and treatment interacted with semi-peak, with round (strata) fixed effects and robust standard errors. Total sign-ups = number of workers who sign up for the external job. EL survey completion: spillover $=1\{$ spillover worker completed the endline survey $\}$. Total non sign-ups $=$ number of non signups selected for the endline survey. EL survey completion: non sign-ups $=1$ non sign-up worker completed the endline survey . Share of non sign-ups surveyed = share of total non sign-ups selected for the endline survey. 
Table B.3. Baseline Characteristics: Sign-Ups and Non Sign-Ups

\begin{tabular}{|c|c|c|c|c|c|c|}
\hline & \multicolumn{3}{|c|}{ Lean } & \multicolumn{3}{|c|}{ Semi-Peak } \\
\hline & $(1)$ & $(2)$ & $(3)$ & $(4)$ & $(5)$ & $(6)$ \\
\hline & Sign-Ups & Difference & pval & Sign-Ups & Difference & pval \\
\hline Ever participate in casual labor market & $\begin{array}{c}1 \\
(0.000)\end{array}$ & $\begin{array}{c}-0.149 \\
(0.061)\end{array}$ & 0.0321 & $\begin{array}{c}0.986 \\
(0.118)\end{array}$ & $\begin{array}{l}-0.215 \\
(0.052)\end{array}$ & 0.000788 \\
\hline Days would like to work in labor market (in next 30 days) & $\begin{array}{l}16.60 \\
(9.005)\end{array}$ & $\begin{array}{l}-4.707 \\
(1.843)\end{array}$ & 0.0268 & $\begin{array}{c}19.10 \\
(8.079)\end{array}$ & $\begin{array}{l}-6.517 \\
(1.917)\end{array}$ & 0.00366 \\
\hline Total wage (Rs.) & $\begin{array}{c}254.6 \\
(67.723)\end{array}$ & $\begin{array}{c}31.27 \\
(10.202)\end{array}$ & 0.0135 & $\begin{array}{c}251.2 \\
(56.468)\end{array}$ & $\begin{array}{c}8.708 \\
(7.347)\end{array}$ & 0.254 \\
\hline Weekly wage earnings & $\begin{array}{c}675.4 \\
(514.302)\end{array}$ & $\begin{array}{c}23.96 \\
(94.285)\end{array}$ & 0.804 & $\begin{array}{c}637.7 \\
(545.994)\end{array}$ & $\begin{array}{c}-20.73 \\
(75.464)\end{array}$ & 0.787 \\
\hline Any activity & $\begin{array}{c}0.389 \\
(0.367)\end{array}$ & $\begin{array}{l}0.0961 \\
(0.101)\end{array}$ & 0.363 & $\begin{array}{c}0.331 \\
(0.352)\end{array}$ & $\begin{array}{r}-0.0408 \\
(0.047)\end{array}$ & 0.400 \\
\hline Employment rate: Hired wage employment & $\begin{array}{c}0.179 \\
(0.282)\end{array}$ & $\begin{array}{c}-0.0564 \\
(0.064)\end{array}$ & 0.395 & $\begin{array}{c}0.176 \\
(0.288)\end{array}$ & $\begin{array}{c}-0.0688 \\
(0.046)\end{array}$ & 0.155 \\
\hline Public works employment & $\begin{array}{c}0.0124 \\
(0.093)\end{array}$ & $\begin{array}{c}0 \\
(0.000)\end{array}$ & 1 & $\begin{array}{c}0.000366 \\
(0.007)\end{array}$ & $\begin{array}{c}0 \\
(0.000)\end{array}$ & 1 \\
\hline Has HH business & $\begin{array}{c}0.859 \\
(0.348)\end{array}$ & $\begin{array}{c}-0.0213 \\
(0.066)\end{array}$ & 0.754 & $\begin{array}{c}0.890 \\
(0.313)\end{array}$ & $\begin{array}{c}-0.0385 \\
(0.021)\end{array}$ & 0.0853 \\
\hline Self employment & $\begin{array}{c}0.164 \\
(0.281)\end{array}$ & $\begin{array}{l}0.0597 \\
(0.039)\end{array}$ & 0.156 & $\begin{array}{c}0.0874 \\
(0.216)\end{array}$ & $\begin{array}{c}0.0283 \\
(0.017)\end{array}$ & 0.120 \\
\hline Landless & $\begin{array}{c}0.506 \\
(0.501)\end{array}$ & $\begin{array}{l}-0.116 \\
(0.043)\end{array}$ & 0.0196 & $\begin{array}{c}0.295 \\
(0.457)\end{array}$ & $\begin{array}{c}-0.0289 \\
(0.034)\end{array}$ & 0.401 \\
\hline HH members (age $12+$ ) & $\begin{array}{c}3.988 \\
(1.696)\end{array}$ & $\begin{array}{l}-0.143 \\
(0.198)\end{array}$ & 0.486 & $\begin{array}{c}3.952 \\
(1.422)\end{array}$ & $\begin{array}{l}-0.175 \\
(0.128)\end{array}$ & 0.189 \\
\hline Social category: Scheduled caste/tribe & $\begin{array}{c}0.817 \\
(0.388)\end{array}$ & $\begin{array}{r}-0.0433 \\
(0.076)\end{array}$ & 0.594 & $\begin{array}{c}0.752 \\
(0.433)\end{array}$ & $\begin{array}{l}-0.166 \\
(0.070)\end{array}$ & 0.0424 \\
\hline
\end{tabular}

Notes: Cols. (1) and (4) present baseline means and standard deviations of worker-level characteristics in control villages for workers who sign up for external jobs in lean and semi-peak months respectively. Cols. (2) and (5) report coefficients from regressing the covariate in each row on a dummy for non sign-ups in lean and semi-peak months respectively, with round (strata) fixed effects and standard errors clustered at the village level. Cols. (3) and (6) report corresponding p-values for the regression coefficients presented in Cols. (2) and (5) respectively. 
TABLE B.4. Wage Effects using Non-Winsorized Wages

\begin{tabular}{|c|c|c|c|c|c|c|}
\hline & $\begin{array}{c}(1) \\
\text { Log cash wage }\end{array}$ & $\begin{array}{c}(2) \\
\text { Log total wage }\end{array}$ & $\begin{array}{c}(3) \\
\text { Log total wage }\end{array}$ & $\begin{array}{c}(4) \\
\text { Total wage }\end{array}$ & $\begin{array}{c}(5) \\
\text { Log total wage }\end{array}$ & $\begin{array}{c}(6) \\
\text { Total wage }\end{array}$ \\
\hline Hiring shock & $\begin{array}{c}-0.0202 \\
(0.021)\end{array}$ & $\begin{array}{c}-0.0113 \\
(0.022)\end{array}$ & $\begin{array}{c}-0.0183 \\
(0.019)\end{array}$ & $\begin{array}{l}-5.632 \\
(3.925)\end{array}$ & $\begin{array}{c}-0.0620 \\
(0.050)\end{array}$ & $\begin{array}{c}-19.24 \\
(11.425)\end{array}$ \\
\hline Hiring shock $*$ Semi-peak & $\begin{array}{l}0.0740 \\
(0.031)\end{array}$ & $\begin{array}{l}0.0676 \\
(0.032)\end{array}$ & $\begin{array}{l}0.0684 \\
(0.029)\end{array}$ & $\begin{array}{c}18.57 \\
(7.595)\end{array}$ & & \\
\hline Hiring Shock $*$ Empl. Level & & & & & $\begin{array}{c}0.457 \\
(0.240)\end{array}$ & $\begin{array}{c}133.3 \\
(57.182)\end{array}$ \\
\hline Sample & Spillover & Spillover & Spillover & Spillover & Spillover & Spillover \\
\hline Baseline controls & No & No & Yes & Yes & Yes & Yes \\
\hline Pval: Shock + Shock*Semi-peak & 0.0232 & 0.0227 & 0.0256 & 0.0472 & . & . \\
\hline SE: Shock + Shock*Semi-peak & 0.0231 & 0.0241 & 0.0219 & 6.379 & . & . \\
\hline Control mean: lean & 5.458 & 5.500 & 5.500 & 253.8 & 5.500 & 253.8 \\
\hline Control mean: semi-peak & 5.428 & 5.504 & 5.504 & 251.6 & 5.504 & 251.6 \\
\hline N (worker-days) & 1543 & 1544 & 1544 & 1545 & 1544 & 1545 \\
\hline
\end{tabular}

Notes: Observations are from the spillover sample (workers who signed up for external jobs but were not offered employment). Total wage $=$ cash + in-kind wages. Controls include worker-level mean employment and wage levels at baseline. Regressions include round (strata) FEs. Standard errors are clustered at the village level in parentheses. 
TABLE B.5. Treatment Effects Restricting to 7-day Recall Window

\begin{tabular}{|c|c|c|c|c|c|c|}
\hline & $\begin{array}{c}(1) \\
\text { Hired wage empl. }\end{array}$ & $\begin{array}{c}(2) \\
\text { Log total wage }\end{array}$ & $\begin{array}{c}(3) \\
\text { Self empl. }\end{array}$ & $\begin{array}{c}(4) \\
\text { Hired wage empl. }\end{array}$ & $\begin{array}{c}(5) \\
\text { Log total wage }\end{array}$ & $\begin{array}{c}(6) \\
\text { Self empl. }\end{array}$ \\
\hline Hiring shock & $\begin{array}{l}0.0518 \\
(0.023)\end{array}$ & $\begin{array}{c}-0.00613 \\
(0.015)\end{array}$ & $\begin{array}{c}-0.0534 \\
(0.018)\end{array}$ & $\begin{array}{r}0.00530 \\
(0.031)\end{array}$ & $\begin{array}{r}0.00616 \\
(0.036)\end{array}$ & $\begin{array}{c}-0.00282 \\
(0.017)\end{array}$ \\
\hline Hiring shock $*$ Semi-peak & $\begin{array}{l}-0.0855 \\
(0.032)\end{array}$ & $\begin{array}{l}0.0450 \\
(0.028)\end{array}$ & $\begin{array}{l}0.0260 \\
(0.025)\end{array}$ & $\begin{array}{r}-0.0658 \\
(0.038)\end{array}$ & $\begin{array}{l}0.0247 \\
(0.044)\end{array}$ & $\begin{array}{l}-0.0236 \\
(0.025)\end{array}$ \\
\hline Sample & Spillover & Spillover & Spillover & Spillover & Spillover & Spillover \\
\hline Baseline controls & Yes & Yes & Yes & Yes & Yes & Yes \\
\hline Pval: Shock + Shock*Semi-peak & 0.140 & 0.0948 & 0.150 & 0.00764 & 0.230 & 0.159 \\
\hline SE: Shock + Shock*Semi-peak & 0.0226 & 0.0229 & 0.0188 & 0.0218 & 0.0254 & 0.0185 \\
\hline Control mean: lean & 0.156 & 5.526 & 0.171 & 0.188 & 5.543 & 0.174 \\
\hline Control mean: semi-peak & 0.232 & 5.502 & 0.107 & 0.222 & 5.529 & 0.130 \\
\hline N (worker-days) & 6944 & 1274 & 6545 & 6196 & 1131 & 6196 \\
\hline
\end{tabular}

Notes: Observations are from the spillover sample (workers who signed up for external jobs but were not offered employment). Hired wage employment $=1$ worker hired that day and paid a wage $\}$. Total wage $=$ cash + in-kind wages. Self employment $=$ $1\{$ worker self-employed that day\}. Cols. (4) to (6) examine impacts two weeks after the end of the hiring shock. Regressions include round (strata) FEs. Standard errors are clustered at the village level in parentheses. 
TABLE B.6. Self-Employment Hours

\begin{tabular}{|c|c|c|c|c|c|c|c|}
\hline & $\begin{array}{c}\text { (1) } \\
\text { Self emp }\end{array}$ & $\begin{array}{c}(2) \\
\text { Self emp }\end{array}$ & $\begin{array}{ll} & (3) \\
\text { Self: } & \text { non-agri }\end{array}$ & $\begin{array}{l}\text { (4) } \\
\text { Self: agri }\end{array}$ & $\begin{array}{c}(5) \\
\text { Self: agri }\end{array}$ & $\begin{array}{c}(6) \\
\text { Self emp }\end{array}$ & $\begin{array}{c}(7) \\
\text { Self emp }\end{array}$ \\
\hline Hiring shock & $\begin{array}{l}-0.164 \\
(0.091)\end{array}$ & $\begin{array}{l}-0.158 \\
(0.105)\end{array}$ & $\begin{array}{l}-0.122 \\
(0.098)\end{array}$ & $\begin{array}{l}-0.145 \\
(0.117)\end{array}$ & $\begin{array}{l}-0.326 \\
(0.149)\end{array}$ & $\begin{array}{l}0.0498 \\
(0.112)\end{array}$ & $\begin{array}{c}-0.000103 \\
(0.100)\end{array}$ \\
\hline $\begin{array}{l}\text { Hiring shock } \\
* \text { Above Median Land Per Capita }\end{array}$ & & & & & $\begin{array}{c}0.341 \\
(0.233)\end{array}$ & & \\
\hline Hiring shock $*$ Semi-peak & $\begin{array}{l}0.0239 \\
(0.127)\end{array}$ & $\begin{array}{r}-0.0166 \\
(0.131)\end{array}$ & $\begin{array}{l}-0.109 \\
(0.145)\end{array}$ & $\begin{array}{c}0.119 \\
(0.126)\end{array}$ & $\begin{array}{c}0.491 \\
(0.180)\end{array}$ & $\begin{array}{l}-0.277 \\
(0.155)\end{array}$ & $\begin{array}{l}-0.202 \\
(0.138)\end{array}$ \\
\hline $\begin{array}{l}\text { Hiring shock* Semi-peak } \\
* \text { Above Median Land Per Capita }\end{array}$ & & & & & $\begin{array}{c}-0.737 \\
(0.299) \\
\end{array}$ & & \\
\hline Sample & Spillover & Spillover & Spillover & Spillover & Spillover & Spillover & Spillover \\
\hline Baseline controls & Yes & Yes & Yes & Yes & Yes & Yes & Yes \\
\hline Recall window (days) & 5 & 7 & 7 & 7 & 7 & 5 & 7 \\
\hline Pval: Shock + Shock*Semi-peak & 0.144 & 0.0451 & 0.0438 & 0.597 & 0.115 & 0.0403 & 0.0407 \\
\hline SE: Shock + Shock*Semi-peak & 0.0946 & 0.0853 & 0.110 & 0.0489 & 0.103 & 0.108 & 0.0961 \\
\hline Control mean: lean & 0.723 & 0.711 & 0.243 & 0.744 & 0.744 & 0.711 & 0.723 \\
\hline Control mean: semi-peak & 0.522 & 0.506 & 0.281 & 0.349 & 0.349 & 0.841 & 0.787 \\
\hline $\mathrm{N}$ & 4675 & 6545 & 3899 & 5838 & 5838 & 4251 & 5951 \\
\hline Level of observations & worker-days & worker-days & worker-days & worker-days & worker-days & worker-days & worker-days \\
\hline
\end{tabular}

Notes: Observations are from the spillover sample (workers who signed up for external jobs but were not offered employment). Self employment $=$ hours worked in self-employment that day. Self employment: non-agri = hours worked in non-agricultural self-employment that day. Self employment: agri = hours worked in agricultural self-employment that day. We restrict the sample to experimental rounds with non-zero self-employment in control villages at endline in Cols. (1), (2), (6) and (7), non-zero non-agricultural self-employment in control villages at endline in Col. (3), and non-zero agricultural self-employment in control villages at endline in Cols. (4)-(5). Cols. (6) and (7) examine impacts two weeks after the end of the hiring shock. Controls include worker-level indicators for any selfemployment activities at baseline. Regressions include round (strata) FE. Standard errors clustered at the village level in parentheses. 
TABLE B.7. Self-Employment

\begin{tabular}{lccc}
\hline \hline & $(1)$ & $(2)$ & $(3)$ \\
& $\begin{array}{c}\text { Self empl: } \\
\text { non-agri }\end{array}$ & $\begin{array}{c}\text { Self empl: } \\
\text { agri }\end{array}$ & $\begin{array}{c}\text { Total Farm } \\
\text { Labor }\end{array}$ \\
\hline Hiring shock & -0.0351 & -0.0925 & -1.940 \\
& $(0.008)$ & $(0.038)$ & $(0.726)$ \\
Hiring shock & & 0.172 & 1.971 \\
* Above Median Land Per Capita & & $(0.064)$ & $(0.903)$ \\
& & & \\
Hiring shock * Semi-peak & 0.00703 & 0.155 & 2.883 \\
& $(0.013)$ & $(0.043)$ & $(0.811)$ \\
Hiring shock * Semi-peak & & -0.228 & -2.948 \\
$*$ Above Median Land Per Capita & & $(0.073)$ & $(1.037)$ \\
\hline Sample & All Potential & All Potential & All Potential \\
& Workers & Workers & Workers \\
Baseline controls & Yes & Yes & Yes \\
Pval: Shock + Shock*Semi-peak & 0.0314 & 0.00562 & 0.0234 \\
SE: Shock + Shock*Semi-peak & 0.0125 & 0.0217 & 0.402 \\
Control mean: lean & 0.0303 & 0.151 & 3.408 \\
Control mean: semi-peak & 0.0589 & 0.0817 & 1.582 \\
N & 11662 & 17774 & 1928 \\
Level of observations & worker-days & worker-days & households \\
\hline \hline
\end{tabular}

Notes: Observations are from all potential workers in the village with appropriate weights. Self employment: non-agri $=1$ \{worker self-employed in nonagriculture that day\}. Self employment: agri $=1$ \{worker self-employed in agriculture that day . Total farm labor $=$ total number of worker-days (own family labor + hired labor) used on the farm over the past week. Controls include worker-level indicators for any self-employment activities at baseline. Regressions include round (strata) FE. Standard errors clustered at the village level in parentheses. 
TABLE B.8. Impacts on Employers

\begin{tabular}{|c|c|c|c|c|c|}
\hline Panel A: No Controls & $\begin{array}{c}(1) \\
\text { Act Done As Many } \\
\text { Times As I Like }\end{array}$ & $\begin{array}{c}(2) \\
\text { Act Done As } \\
\text { Early As I Like }\end{array}$ & $\begin{array}{c}(3) \\
\text { Hire From } \\
\text { Outside Vill }\end{array}$ & $\begin{array}{c}(4) \\
\text { Trouble Hiring } \\
\text { (Days) }\end{array}$ & $\begin{array}{c}\quad(5) \\
\text { Worker } \\
\text { Rating }\end{array}$ \\
\hline Hiring shock & $\begin{array}{c}0.0316 \\
(0.013)\end{array}$ & $\begin{array}{c}0.00824 \\
(0.023)\end{array}$ & $\begin{array}{c}0.00789 \\
(0.027)\end{array}$ & $\begin{array}{c}-0.0386 \\
(0.070)\end{array}$ & $\begin{array}{c}-0.0105 \\
(0.082)\end{array}$ \\
\hline Hiring shock $*$ Semi-peak & $\begin{array}{r}-0.0497 \\
(0.017)\end{array}$ & $\begin{array}{r}-0.0548 \\
(0.039)\end{array}$ & $\begin{array}{l}0.0568 \\
(0.031)\end{array}$ & $\begin{array}{c}0.0444 \\
(0.083)\end{array}$ & $\begin{array}{c}0.173 \\
(0.115)\end{array}$ \\
\hline Pval: Shock + Shock*Semi-peak & 0.101 & 0.145 & 0.000142 & 0.898 & 0.0472 \\
\hline SE: Shock + Shock*Semi-peak & 0.0108 & 0.0314 & 0.0159 & 0.0446 & 0.0801 \\
\hline Control mean: lean & 0.972 & 0.972 & 0.0758 & 0.190 & 3.639 \\
\hline Control mean: semi-peak & 0.987 & 0.962 & 0.0363 & 0.239 & 3.266 \\
\hline $\mathrm{N}$ & 678 & 678 & 1029 & 1029 & 1264 \\
\hline Level of observations & emp-activity & emp-activity & employer & employer & worker-day \\
\hline \multicolumn{6}{|l|}{ Panel B: With Controls } \\
\hline Hiring shock & $\begin{array}{l}0.0247 \\
(0.012)\end{array}$ & $\begin{array}{r}-0.0131 \\
(0.036)\end{array}$ & $\begin{array}{c}0.00203 \\
(0.027)\end{array}$ & $\begin{array}{c}-0.0610 \\
(0.070)\end{array}$ & \\
\hline Hiring shock $*$ Semi-peak & $\begin{array}{r}-0.0487 \\
(0.017)\end{array}$ & $\begin{array}{r}-0.0427 \\
(0.048)\end{array}$ & $\begin{array}{l}0.0635 \\
(0.031)\end{array}$ & $\begin{array}{l}0.0854 \\
(0.084)\end{array}$ & \\
\hline Pval: Shock + Shock*Semi-peak & 0.0599 & 0.0819 & 0.000128 & 0.606 & \\
\hline SE: Shock + Shock* Semi-peak & 0.0124 & 0.0313 & 0.0159 & 0.0469 & \\
\hline Control mean: lean & 0.972 & 0.972 & 0.0758 & 0.190 & \\
\hline Control mean: semi-peak & 0.987 & 0.962 & 0.0363 & 0.239 & \\
\hline $\mathrm{N}$ & 678 & 678 & 1029 & 1029 & \\
\hline Level of observations & emp-activity & emp-activity & employer & employer & \\
\hline
\end{tabular}

Notes: Observations in Cols. (1)-(4) are from a sample of employers surveyed in the village. Observations in Col.

(5) are from the spillover sample (workers who signed up for external jobs but were not offered employment). Activity done as many times as I like $=1$ employer reports being able to complete a particular activity as frequently as he liked $\}$. Activity done as early as I like $=1\{$ employer reports being able to complete a particular activity as early as he liked $\}$. Hire from outside village $=1$ employer hired from outside the village for any activity $\}$. Trouble hiring $=$ number of days the employer reports having trouble hiring workers, in the past 10 days. Worker rating = ability rating of the worker, averaged across all surveyed employers in the village. Panel A presents regression results with no controls, while Panel B presents regression results with employer-level controls for which there is imbalance. Regressions include round (strata) FEs. Standard errors are clustered at the village level in parentheses. 
TABLE B.9. Employment Spillovers: Heterogeneous Impacts by Ability

\begin{tabular}{lccc}
\hline \hline & \multicolumn{3}{c}{ Dependent variable: Hired wage employment } \\
& \multicolumn{3}{c}{ High ability proxy } \\
\cline { 2 - 4 } & $(1)$ & $(2)$ & $(3)$ \\
& Employer Rating & Employment Rate & Wages \\
\hline Hiring shock & 0.0847 & 0.0526 & 0.0628 \\
& $(0.022)$ & $(0.018)$ & $(0.018)$ \\
Hiring shock * Semi-peak & -0.103 & -0.0662 & -0.0780 \\
& $(0.040)$ & $(0.029)$ & $(0.031)$ \\
High ability proxy & & & 0.0521 \\
& 0.0246 & 0.0752 & $(0.013)$ \\
Hiring Shock* High ability proxy & $(0.018)$ & $(0.018)$ & -0.00906 \\
& -0.00450 & -0.0441 & $(0.025)$ \\
Semi-peak* High ability proxy & $(0.030)$ & $(0.030)$ & 0.0644 \\
& & & $(0.024)$ \\
Hiring shock* Semi-peak* High ability proxy & -0.0139 & 0.0470 & $(0.024)$ \\
& $(0.023)$ & 0.0495 & 0.00975 \\
& & & $(0.0309$ \\
\hline Sample & $(0.035)$ & $(0.041)$ & Spillover \\
Baseline controls & Spillover & Spillover & No \\
Pval: Shock + Shock*Semi-peak & No & 0.540 & 0.548 \\
SE: Shock + Shock*Semi-peak & 0.586 & 0.0221 & 0.0253 \\
Control mean: lean & 0.0334 & 0.145 & 0.145 \\
Control mean: semi-peak & 0.134 & 0.216 & 0.216 \\
N (worker-days) & 0.228 & 8906 & 8906 \\
\hline \hline
\end{tabular}

Notes: Observations are from the spillover sample (workers who signed up for external jobs but were not offered employment). We use three different worker-level proxies for high ability: standardized quality rating averaged across all survey employers in the village in Col.(1), standardized mean employment levels at baseline in Col. (2), and standardized mean wage levels at baseline in Col. (3). Regressions include round (strata) FEs. Standard errors are clustered at the village level in parentheses. 
TABLE B.10. Impacts on Male Household Members

\begin{tabular}{lccccc}
\hline \hline & $(1)$ & $(2)$ & $(3)$ & $(4)$ & $(5)$ \\
& $\begin{array}{c}\text { Work in casual } \\
\text { labor market }\end{array}$ & $\begin{array}{c}\text { Work in casual } \\
\text { labor market }\end{array}$ & $\begin{array}{c}\text { Work on } \\
\text { own land }\end{array}$ & $\begin{array}{c}\text { Work in } \\
\text { Helsiness }\end{array}$ & $\begin{array}{c}\text { Self } \\
\text { employment }\end{array}$ \\
\hline Hiring shock & 0.0188 & 0.0287 & -0.0342 & -0.00263 & -0.0364 \\
& $(0.013)$ & $(0.012)$ & $(0.017)$ & $(0.005)$ & $(0.017)$ \\
Hiring shock * Semi-peak & & & & & $0.017)$ \\
& -0.0301 & -0.0487 & 0.0433 & -0.000350 & 0.0419 \\
& $(0.023)$ & $(0.028)$ & $(0.018)$ & $(0.008)$ & $(0.020)$ \\
\hline Sample & Spillover & Spillover & Spillover & Spillover & Spillover \\
Baseline controls & Yes & Yes & Yes & Yes & Yes \\
Pval: Shock + Shock*Semi-peak & 0.544 & 0.423 & 0.151 & 0.680 & 0.602 \\
SE: Shock + Shock*Semi-peak & 0.0184 & 0.0247 & 0.00618 & 0.00718 & 0.0104 \\
Control mean: lean & 0.119 & 0.146 & 0.0980 & 0.0137 & 0.111 \\
Control mean: semi-peak & 0.169 & 0.218 & 0.0312 & 0.0151 & 0.0442 \\
N (workers) & 1660 & 1296 & 1690 & 1750 & 1752 \\
\hline \hline
\end{tabular}

Notes: Observations are from male household members (above the age of 12) of workers in the spillover sample (workers who signed up for external jobs but were not offered employment). Controls in Cols. (1)(2) include worker-level mean employment and wage levels at baseline. Controls in Cols. (3)-(5) include indicators for any self-employment activities at baseline. In Col. (2), we restrict the sample to household members who report participating in the casual labor market. Self-employment $=1$ wwork on own land or in household business\}. Regressions include round (strata) FEs. Standard errors are clustered at the village level in parentheses. 
TABLE B.11. Differential Impacts of NREGS by Labor Market Slack

\begin{tabular}{|c|c|c|c|c|c|}
\hline & $\begin{array}{c}(1) \\
\text { Public Works } \\
\text { Days }\end{array}$ & $\begin{array}{c}(2) \\
\text { Casual } \\
\text { Wage }\end{array}$ & $\begin{array}{c}(3) \\
\text { Casual Days } \\
\text { Worked }\end{array}$ & $\begin{array}{c}(4) \\
\text { Casual Agri. } \\
\text { Days }\end{array}$ & $\begin{array}{c}(5) \\
\text { Self-Empl. } \\
\text { Days }\end{array}$ \\
\hline NREGA & $\begin{array}{l}0.0213 \\
(0.010)\end{array}$ & $\begin{array}{c}-0.618 \\
(1.009)\end{array}$ & $\begin{array}{l}0.0678 \\
(0.054)\end{array}$ & $\begin{array}{c}-0.00650 \\
(0.047)\end{array}$ & $\begin{array}{l}-0.206 \\
(0.071)\end{array}$ \\
\hline NREGA x High Casual Employment & $\begin{array}{c}0.00906 \\
(0.013)\end{array}$ & $\begin{array}{c}2.594 \\
(1.052)\end{array}$ & $\begin{array}{r}-0.0980 \\
(0.059)\end{array}$ & $\begin{array}{l}-0.121 \\
(0.061)\end{array}$ & $\begin{array}{l}0.0923 \\
(0.080)\end{array}$ \\
\hline Control Mean & 0.0121 & 72.00 & 1.071 & 0.652 & 4.738 \\
\hline Test: NREGA + NREGA x High Cas. Empl. & 0.0132 & 0.0554 & 0.609 & 0.0308 & 0.152 \\
\hline Observations & 353180 & 64634 & 353180 & 353180 & 329177 \\
\hline
\end{tabular}

Notes: Observations are from prime-age individuals surveyed in rounds 61 and 64 of Schedule 10 of the National Sample Survey (NSS), with sampling weights. Regressions include district and month-by-year fixed effects, as well as a vector of controls including worker characteristics by round (gender, education, age), baseline agricultural yields by round, and district-by-month baseline means of casual employment, wages, and self-employment. Standard errors are clustered at the district level in parentheses. 
TABlE B.12. Treatment Effects Using All Experimental Rounds

\begin{tabular}{|c|c|c|c|c|c|c|}
\hline & $\begin{array}{c}(1) \\
\text { Log total } \\
\text { wage }\end{array}$ & $\begin{array}{c}(2) \\
\text { Hired wage } \\
\text { employment }\end{array}$ & $\begin{array}{c}(3) \\
\text { Hired wage } \\
\text { employment }\end{array}$ & $\begin{array}{c}(4) \\
\text { Self } \\
\text { employment }\end{array}$ & $\begin{array}{c}(5) \\
\text { Invol unempl } \\
\text { (traditional) }\end{array}$ & $\begin{array}{c}(6) \\
\text { Invol unempl } \\
\text { (alternate) }\end{array}$ \\
\hline Hiring shock & $\begin{array}{c}-0.0181 \\
(0.019)\end{array}$ & $\begin{array}{l}0.0540 \\
(0.018)\end{array}$ & $\begin{array}{c}0.0101 \\
(0.022)\end{array}$ & $\begin{array}{c}-0.0331 \\
(0.019)\end{array}$ & $\begin{array}{c}-0.0339 \\
(0.027)\end{array}$ & $\begin{array}{r}-0.0625 \\
(0.026)\end{array}$ \\
\hline Hiring shock $*$ Semi-peak & $\begin{array}{c}0.0673 \\
(0.028)\end{array}$ & $\begin{array}{r}-0.0681 \\
(0.028)\end{array}$ & $\begin{array}{r}-0.0551 \\
(0.025)\end{array}$ & $\begin{array}{c}-0.00737 \\
(0.026)\end{array}$ & $\begin{array}{c}0.0529 \\
(0.037)\end{array}$ & $\begin{array}{l}0.0793 \\
(0.037)\end{array}$ \\
\hline Sample & Spillover & Spillover & All Workers & Spillover & Spillover & Spillover \\
\hline Baseline controls & Yes & Yes & Yes & Yes & Yes & Yes \\
\hline Pval: Shock + Shock*Semi-peak & 0.0189 & 0.526 & 0.000629 & 0.0263 & 0.453 & 0.523 \\
\hline SE: Shock + Shock*Semi-peak & 0.0204 & 0.0221 & 0.0125 & 0.0178 & 0.0252 & 0.0262 \\
\hline Control mean: lean & 5.500 & 0.145 & 0.135 & 0.139 & 0.482 & 0.580 \\
\hline Control mean: semi-peak & 5.502 & 0.209 & 0.185 & 0.112 & 0.413 & 0.553 \\
\hline N (worker-days) & 1603 & 9466 & 22398 & 8941 & 9466 & 9466 \\
\hline
\end{tabular}

Notes: This table presents regression results including two experimental rounds that were excluded from the main analysis because we were not able to complete survey work (see Appendix C). Observations in Cols. (1)-(2) and (4)-(6) are from the spillover sample (workers who signed up for external jobs but were not offered employment). Observations in Col. (3) are from all potential workers in the village with appropriate weights. Controls in Cols. (1)-(2) and (5)-(6) include worker-level mean employment and wage levels at baseline. Controls in Col. (3) include worker-level and village-level mean employment and wage levels at baseline. Controls in Col. (4) include indicators for any self-employment activities at baseline. Regressions include round (strata) FEs. Standard errors clustered at the village level in parentheses. 
TABLE B.13. Employer Characteristics

\begin{tabular}{|c|c|c|c|c|c|c|}
\hline & \multicolumn{3}{|c|}{ Lean } & \multicolumn{3}{|c|}{ Semi-Peak } \\
\hline & $(1)$ & $(2)$ & $(3)$ & $(4)$ & $(5)$ & (6) \\
\hline & No hiring shock & Difference & Pval & No hiring shock & Difference & Pval \\
\hline Landholdings (acres) & $\begin{array}{c}2.634 \\
(1.696)\end{array}$ & $\begin{array}{l}0.308 \\
(0.177)\end{array}$ & 0.0947 & $\begin{array}{c}2.631 \\
(1.696)\end{array}$ & $\begin{array}{r}-0.0506 \\
(0.109)\end{array}$ & 0.645 \\
\hline HH members (age $12+$ ) & $\begin{array}{c}4.199 \\
(1.508)\end{array}$ & $\begin{array}{c}0.178 \\
(0.124)\end{array}$ & 0.167 & $\begin{array}{c}4.254 \\
(1.508)\end{array}$ & $\begin{array}{l}0.265 \\
(0.114)\end{array}$ & 0.0258 \\
\hline Fraction of randomly selected workers given a rating & $\begin{array}{l}0.725 \\
(0.250)\end{array}$ & $\begin{array}{l}-0.0151 \\
(0.039)\end{array}$ & 0.702 & $\begin{array}{c}0.791 \\
(0.250)\end{array}$ & $\begin{array}{l}0.0366 \\
(0.029)\end{array}$ & 0.209 \\
\hline Fraction of randomly selected workers ever hired & $\begin{array}{c}0.257 \\
(0.221)\end{array}$ & $\begin{array}{r}0.00727 \\
(0.031)\end{array}$ & 0.817 & $\begin{array}{l}0.216 \\
(0.221)\end{array}$ & $\begin{array}{l}0.0116 \\
(0.016)\end{array}$ & 0.473 \\
\hline Ever participate in casual labor market & $\begin{array}{c}0.569 \\
(0.496)\end{array}$ & $\begin{array}{r}-0.0488 \\
(0.043)\end{array}$ & 0.266 & $\begin{array}{c}0.495 \\
(0.496)\end{array}$ & $\begin{array}{c}-0.000666 \\
(0.035)\end{array}$ & 0.985 \\
\hline Occupation: Self-emp (agri) & $\begin{array}{c}0.611 \\
(0.489)\end{array}$ & $\begin{array}{r}-0.0208 \\
(0.013)\end{array}$ & 0.123 & $\begin{array}{c}0.620 \\
(0.489)\end{array}$ & $\begin{array}{r}-0.0176 \\
(0.006)\end{array}$ & 0.00702 \\
\hline Occupation: Self-emp (non-agri) & $\begin{array}{l}0.0616 \\
(0.241)\end{array}$ & $\begin{array}{l}-0.0191 \\
(0.019)\end{array}$ & 0.316 & $\begin{array}{l}0.0693 \\
(0.241)\end{array}$ & $\begin{array}{c}-0.00483 \\
(0.013)\end{array}$ & 0.718 \\
\hline Occupation: Laborer & $\begin{array}{c}0.303 \\
(0.461)\end{array}$ & $\begin{array}{r}-0.0556 \\
(0.041)\end{array}$ & 0.192 & $\begin{array}{c}0.274 \\
(0.461)\end{array}$ & $\begin{array}{r}-0.0197 \\
(0.026)\end{array}$ & 0.463 \\
\hline Social category: Scheduled caste/tribe & $\begin{array}{c}0.332 \\
(0.472) \\
\end{array}$ & $\begin{array}{l}-0.175 \\
(0.044) \\
\end{array}$ & 0.000572 & $\begin{array}{c}0.281 \\
(0.472) \\
\end{array}$ & $\begin{array}{r}-0.0300 \\
(0.039) \\
\end{array}$ & 0.444 \\
\hline
\end{tabular}

Notes: Observations are from the employer survey. Cols. (1) and (4) present means and standard deviations of employer-level characteristics in control villages in lean and semi-peak months respectively. Cols. (2) and (5) report coefficients from regressing the covariate in each row on a dummy for treatment in lean and semi-peak months respectively, with round (strata) fixed effects and standard errors clustered at the village level. Cols. (3) and (6) report corresponding p-values for the regression coefficients presented in Cols. (2) and (5) respectively. 


\section{Appendix C. Implementation Protocols}

Recruitment of study participants. Several days prior to the first day of work, the external jobs are advertised in villages through flyers, village meetings, and door-to-door visits. First, flyers containing basic information about the job opportunity (nature of work, duration, hours per day, location, daily wage etc.) are distributed to all households. Next, a meeting is held in a central location within the village. During this meeting, more information is given to interested workers. For example, they are informed that the job opportunity is one-time only and employment is not guaranteed - the number of workers hired would depend on the needs of local contractors, and job offers would be randomly assigned among those who sign up using a lottery. ${ }^{45}$ Lastly, door-to-door visits are made to ensure that all households in the village have received information about the external job opportunity. Male workers who are interested in the job are encouraged to sign up at the village meeting or during door-to-door visits. Workers who are under the age of 18 or above the age of 65 are ineligible.

We use a computer to randomize assignment of eligible sign-ups to one of three groups: (1) workers who will be offered a job; (2) workers who might be offered a job (waitlist); and (3) workers who will never be offered a job. We draw from the group 2 roster in the event that a worker from group 1 opts out of the external job. Workers in group 3 constitutes our spillover sample.

Description of external jobs. The external jobs take place in factory workshops within 15 kilometers of our study villages. Workers are employed full-time (5 days a week) for 2-4 weeks, and they engage in low-skill manufacturing of products such as ropes, brooms, disposable plates and floor mats. All output produced by workers is sold by partnering contractors, who set production standards. Workers are paid a flat daily wage for attendance, in accordance with the typical pay structure in the area. There are no strict production minimums imposed on workers, though workers can be fired for excessive absences (more than three days in a row) or disruptive behavior.

At any point in time, a total of approximately 30 workers are recruited into a worksite this comprises of workers from both treatment and control villages within an experimental round. In experimental rounds where the number of recruited workers across both treatment and control villages is less than 30, we hire additional workers from nearby villages until we reach the capacity limit at the factory workshop.

More details on the external jobs can be found in Breza et al. (2018).

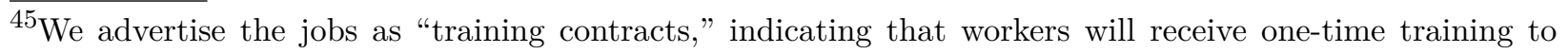
produce a low-skill manufacturing good during their employment period. This concept is familiar in this context, and is viewed as a one-time opportunity since one would not receive training more than once. See Breza et al. (2018) for further details.
} 
Worker surveys. We conduct surveys with all eligible workers who sign up. We also conduct surveys with a random sample of potential workers in the village who do not sign up for the job. For this sample, the enumerators follow a left-hand rule - they start at the first household on the left as they enter the village, and approach every three households thereafter. The survey is conducted with a prime-age male household member who is working in any capacity - this includes work in the casual labor market, self-employment or salaried work. If a member of the household is part of the spillover sample, the household is skipped.

Timeline of worker surveys. We conduct three waves of surveys: (1) baseline surveys at the start of the hiring shock; (2) endline surveys during the final two weeks of the hiring shock; and (3) post-intervention surveys two weeks after the end of the hiring shock. ${ }^{46}$ Surveys are conducted privately with workers at their residence. To compensate workers for their time as well as to minimize survey attrition, workers are given a small gift upon completion of the post-intervention survey.

A subset of baseline surveys were conducted immediately after the external jobs began. Recall that in each of the surveys, workers are asked to describe their employment activity separately for each day for the past 10 days. As such, part of the employment recall in those surveys included days during which the external job had already commenced. We restrict baseline data used in regressions to worker-days that occurred before the external jobs began. As we document in the paper, our wage and employment effects are similar with or without baseline controls.

Changes to worker survey instruments. In the first 9 experimental rounds, we collected recall data for the past 14 days. We shortened this to 10 days for the next 9 rounds, and further shortened this to 7 days for the remaining rounds.

As mentioned above, we began conducting the post-intervention worker survey in experimental round 3. For the first six rounds thereafter, the survey was conducted 1-2 months after the end of the hiring shock. We shortened this to two weeks for the remaining experimental rounds.

Employer surveys. In addition to worker surveys, we survey a subset of agricultural employers in the village at endline (i.e. during the final two weeks of the hiring shock). Our enumerators first consult a village resident to obtain a (partial) list of employers who hire agricultural workers in each village. Using this listing, we generate a roster with a randomized ordering of employers. Enumerators then conduct employer surveys following the order as stated in the roster, with a stopping rule of 20 employer surveys per village. In some cases, there are

\footnotetext{
${ }^{46}$ We added the post-intervention survey from experimental round 3 onwards.
} 
fewer than 20 listed employers per village, so the total number of surveys completed is less than 20. The mean number of employer surveys completed per village is 18 .

The employer survey includes a detailed hiring grid, in which employers describe each activity for which they required labor in the past 30 days. This includes data on labor use (number of workers, days worked, hiring location), cash wages and in-kind payments made to hired workers for each activity, as well as whether the activity was completed as early and as frequently as they would have liked. All regressions using the employer sample are unweighted.

Changes to implementation protocols. In the last 11 experimental rounds, we conduct a census of all households in our study villages prior to advertising the external job. Data from this census exercise allows us to:

(1) identify a random sample of potential workers in the village. We generate a roster consisting of prime-age males village residents who do not sign up for the job. We do not impose any condition on work status, as we did in earlier rounds.

(2) identify a sample of agricultural employers in the village. We generate a roster consisting of the five largest employers in the village (based on the number of workerdays they report hiring for a paid wage in the most recent harvest season), and a random sampling of the remaining employers in the village.

This supersedes the protocol used to sample non-sign ups and agricultural employers outlined above.

Implementation issues. We faced issues conducting end line worker surveys in two experimental rounds and were only able to survey a small subset of intended participants. One village previously had a negative experience with outsiders who promised gifts if the village residents converted to a particular religion. As such, residents in this village got suspicious (our standard survey protocol was to offer respondents a small gift upon completion of the surveys) and refused to let our enumerators into the village to conduct surveys. In another village, several village residents who were not part of our study sample did not want surveys to be conducted in their village. While the respondents themselves did not have any issues participating in the survey, the hostility from other residents in the village made it difficult and potentially unsafe for our enumerators to enter the village. As such, we decided to halt data collection in this village.

In Appendix Table B.12, we present regression results including the two experimental rounds, discussed here, that were excluded from the main analysis because we were not able to complete survey work. Our results are robust to the inclusion of these two rounds. 


\section{Appendix D. Construction of Census Variables}

We use village-level data on demographic and economic indicators from the 2011 Indian Population Census. This includes data on village size (population and number of households), caste composition, literacy, as well as worker counts.

As described in the 2011 Census meta data, ${ }^{47}$ workers are defined as "all persons (irrespective of age and sex) who participated in any economically productive activity for any length of time during the reference period." The reference period corresponds to the one year preceding the date of survey enumeration. Workers who "worked for more than 6 months in the reference period" are referred to as main workers. Workers are further classified into four categories:

(1) agricultural laborers - this refers to individuals who "work on another person's land for wages in money or kind or share. She or he has no risk in the cultivation, but merely works in another person's land for wages"

(2) cultivators - this refers to individuals who are "engaged in cultivation of land owned or held from Government or held from private persons or institutions for payments in money, kind or share"

(3) workers in household industry - household industry is defined as "an industry conducted by one or more members of the household at home or within the village in rural areas and only within the precincts of the house where the household lives in urban areas"

(4) other workers - this refers to workers other than those in categories (1)-(3). Examples include work in the public sector, manufacturing, construction etc.

We construct several outcome variables using this data:

- Male population share: male population/village population

- Literacy rate: literate population/village population

- Worker share: all workers/village population

- Male worker share: male workers/all workers

- Main worker share: main workers/all workers

- Agricultural labor share: agricultural laborers/all workers

- Cultivator share: cultivators/all workers

- Non-farm self-employment share: workers in household industry/all workers

- Other workers share: other workers/all workers

${ }^{47}$ The 2011 Census meta data is available at https://www.censusindia.gov.in/2011census/HLO/ Metadata_Census_2011.pdf. 


\section{Appendix E. Implied Aggregate Demand and Supply Elasticities}

The nature of our shock allows us to back out both aggregate demand and supply elasticities during semi-peak periods, if we are willing to assume competitive equilibrium. While this is a strong assumption - and one that is not required in our main analysis - there are few opportunities in the literature to measure these implied elasticities, so we include these estimates here for completeness. Of course, as with all such analyses, the credibility of these estimates relies on the extent to which one believes in the underlying assumption of competitive equilibrium in semi-peak times.

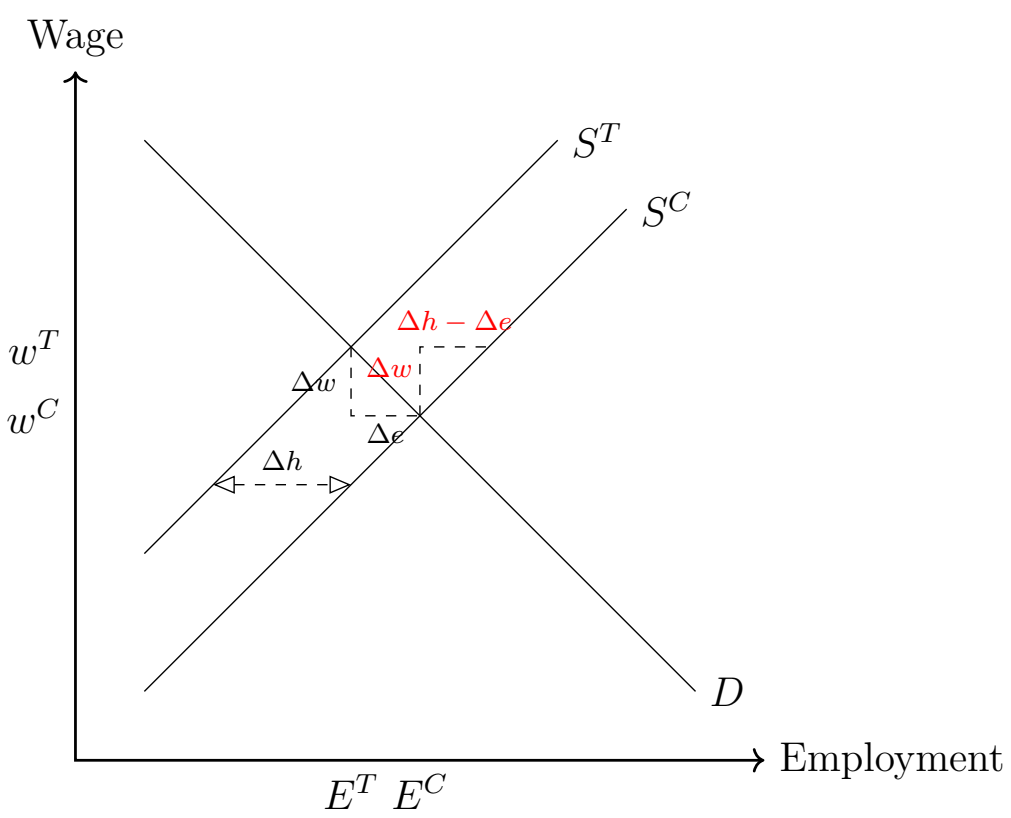

Figure A.8. Aggregate Elasticities

Note: Figure illustrates how we can identify aggregate demand and supply elasticities during semi-peak months, under the assumption of competitive equilibrium. $\Delta w$ and $\Delta e$ denote the observed change in wages and employment respectively as a result of the hiring shock. The shock traces out the inverse slope of the demand curve, $\frac{\Delta e}{\Delta w}$. $\Delta h$ denotes the size of the shift in aggregate supply. Given $\Delta h$, a simple geometric argument shows that the slope of the supply curve is $\frac{\Delta w}{\Delta h-\Delta e}$.

Appendix Figure A.8 shows how we can identify both the aggregate demand and supply elasticities under this strong assumptions. We denote the observed change in wages between treatment and control as $\Delta w$ and the change in aggregate employment as $\Delta e$. Given that our treatment shifted the supply curve inward, the shock traces out the (inverse) slope of the demand curve $\frac{\Delta e}{\Delta w}$. That supply shocks identify demand elasticities is well known. However, using arguments similar to Zoutman et al. (2018), we can also back out an implied supply elasticity as well. Because we know the exact shock size - how many workers were employed 
in our external jobs and those workers' counterfactual employment rates - we can directly measure the size of the shift in aggregate supply $\Delta h{ }^{48}$ Given $\Delta h$, a simple geometric argument shows that the inverse slope of the supply curve is $\frac{\Delta w}{\Delta h-\Delta e}$.

Incorporating the impacts of our experimental shocks into this framework, the implied aggregate supply elasticity is 0.03 , though clearly there is substantial noise around this estimate. This very small supply elasticity is consistent with the development literature. ${ }^{49}$ The implied aggregate demand elasticity is -4.16 , a very large magnitude relative to the literature. ${ }^{50}$ If we believe that the magnitude of this implied demand elasticity is "too large," then one of our assumptions is likely unreasonable. First, under partially segmented markets, in semi-peak periods, employers may substitute toward workers outside of the village, who typically command higher wages. This would bias our measure of the change in employment in semi-peak times, leading to an overesimtate of the demand elasticity. Second, relaxing the assumption of market clearing could also help to explain these large demand elasticity magnitudes. One departure from market clearing that would yield an unbiased supply elasticity but distort the implied demand elasticity is monopsony. ${ }^{51}$

In addition to the caveats about underlying assumptions, our estimates are measured with considerable noise. We consequently view them as suggestive. More generally, we intend this stylized exercise to be illustrative - demonstrating how knowing the exact shock size enables one to recover both elasticities with one source of variation.

\footnotetext{
${ }^{48}$ Recall that our experimental job paid workers a premium. Therefore $\Delta h$ is not equivalent to the fraction of laborers who took our job in treatment versus control, but instead the fraction of days they would have worked at the market wage in absence of the external job.

${ }^{49}$ For example, Goldberg (2016) measures a supply elasticity of 0.17 in rural Malawi.

${ }^{50}$ The demand elasticity of Imbert and Papp (2020), obtained from a structural model of the migration response to NREGA, is an imprecisely estimated -0.22. Kaur (2019)'s estimate is -1.17.

${ }^{51}$ Under monopsony, employment levels are pinned down by the aggregate supply curve facing the employer. However, changes in employment and wages do not trace out the demand curve. In fact, wages fall by less and employment falls by more under monopsony versus market clearing (Appendix Figure A.2), leading to an implied demand elasticity that is too large. This is consistent with the view of Muralidharan et al. (2020).
} 